\title{
PEÑAS BLANCAS Y SUS NARRATIVAS: LA CONSTRUCCIÓN DEL DISCURSO SOBRE EL PATRIMONIO CULTURAL Y LA MEMORIA LOCAL EN QUEBRADA DE HUMAHUACA (JUJUY, ARGENTINA)
}

\author{
PEÑAS BLANCAS AND THEIR NARRATIVES: THE CONSTRUCTION OF THE \\ DISCOURSE ON THE CULTURAL HERITAGE AND THE LOCAL MEMORY IN \\ QUEBRADA DE HUMAHUACA (JUJUY, ARGENTINA)
}

\author{
Clara Elisa Mancini ${ }^{*}$,Verónica Judith Acevedo ${ }^{* *}$ y Mariel Alejandra López ${ }^{*}$
}

\begin{abstract}
Peñas Blancas es un sitio conocido como Antigal, Pucara o Pueblo Viejo de Humahuaca, ubicado en la Quebrada de Humahuaca (Jujuy, Argentina). Durante gran parte del siglo XX, algunos de los discursos concernientes al sitio han sido más reconocidos que otros, aunque en la actualidad se encuentran en manifiesta tensión. Por ello, el objetivo de este trabajo es exponer las diferentes narrativas respecto del sitio que circularon desde principios del siglo XX a la actualidad, en relación con los diferentes vínculos que se crean con él y el territorio del que forma parte. Para ello apelamos a la complementación de distintos tipos de fuentes y resultados de investigación: notas periodísticas, trabajos académicos previos, así como observaciones en el sitio y entrevistas realizados en el departamento de Humahuaca.
\end{abstract}

Palabras claves: Narrativas, Discurso Patrimonial Autorizado, Patrimonio Cultural, Memoria.

Peñas Blancas is a site known as Antigal, Pucara or Pueblo Viejo of Humahuaca, located in the Quebrada de Humahuaca (Jujuy, Argentina). For much of the twentieth century, some discourses about this site have been more recognized than others, but today they are in evident tension. Then, the aim of this paper is to present the different narratives about the site that have circulated since the early twentieth century to the present, in relationship with the diverse bonds that are created between the site and the territory that it belongs to. For this we appeal to the complementation of different types of sources and research results: journalistic notes, previous academic work as well as on-site observations and interviews conducted in the department of Humahuaca.

Key words: Narratives, Authorized Heritage Discourse, Cultural Heritage, Memory.

\section{Introducción}

El sitio conocido como Peñas Blancas se encuentra en el sector norte de la Quebrada de Humahuaca, Jujuy, Argentina (Figura 1). Aunque las comunidades lo reconocen como el Antigal de Peñas Blancas, la literatura arqueológica lo denominó Peñas Blancas, Pucara de Humahuaca o Pueblo Viejo de Humahuaca a partir del conocimiento de las únicas excavaciones realizadas en él entre 1931 y 1944 (Gatto 1941; Márquez Miranda 1945). Durante las últimas décadas varios arqueólogos de la región lo han incluido cronológicamente dentro de los períodos de Desarrollos Regionales e Inca basada en sus rasgos arquitectónicos y materiales de superficie (Palma 1991; Nielsen 2001; Raffino 2007).
Este trabajo se originó por los diferentes discursos acerca de los sitios arqueológicos que hallamos durante los trabajos de campo en la Quebrada de Humahuaca y, más específicamente, en torno al sitio Peñas Blancas. Como señaló Kojan (2008:82), no hay "posiciones externas" en la examinación del pasado, todos estamos comprometidos con las consideraciones contingentes del pasado y formamos parte de las narrativas que escribimos, circulamos, reproducimos. Ciertos discursos han sido más reconocidos que otros, lo que Smith llamó "Discurso Patrimonial Autorizado" (DPA). Se trata de un discurso "involucrado en la legitimación y regulación de narrativas históricas y culturales, y el trabajo que estas narrativas hacen en mantener y negociar los valores y las jerarquías que estas apuntalan".

\footnotetext{
* Consejo Nacional de Investigaciones Científicas y Técnicas (CONICET), Universidad de Buenos Aires (UBA), Facultad de Filosofía y Letras (FFyL), Instituto de Arqueología. Buenos Aires, Argentina. Correo electrónico: claraemancini@gmail.com; marielarqueologia@yahoo.com.ar

** Universidad de Buenos Aires, Facultad de Filosofía y Letras, Instituto de Arqueología. Buenos Aires, Argentina. Correo electrónico: veronicaacevedo@speedy.com.ar
} 


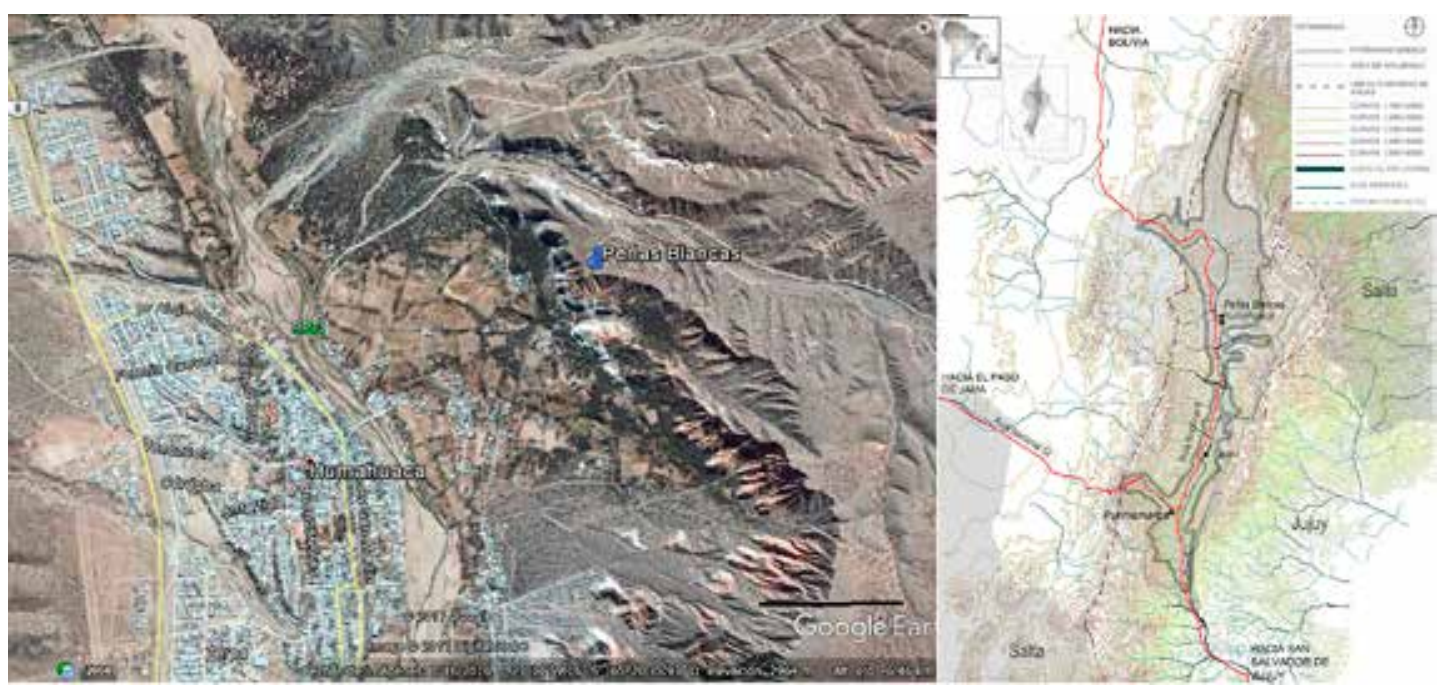

Figura 1. Ubicación de Peñas Blancas en Jujuy, Argentina. Izquierda: Ubicación sobre imagen de Google Earth. Derecha: Ubicación del sitio en la Quebrada de Humahuaca, Jujuy, Argentina (a partir de Tommei 2016).

(Smith 2012:3 [traducción propia]). Este conflicto de intereses en torno a un lugar y las narrativas del pasado asociadas trasciende la historia de la disciplina arqueológica. De hecho, históricamente en la región existen algunos antecedentes respecto de los discursos encontrados entre los líderes étnicos y los religiosos europeos en torno a la ocupación de estos sitios en los que las comunidades vivían antes de la conquista. Entre las razones por las que los europeos pretendían su abandono influyó no solo la legislación acerca de la extirpación de idolatrías, sino, además, el establecimiento de una nueva forma de vida que no era consistente con la anterior (ver por ejemplo López 2011). No obstante todo ello, en este trabajo nos interesa precisar cómo Peñas Blancas se construyó como patrimonio cultural, proceso que cobró forma con las investigaciones arqueológicas a inicios del siglo XX. Por ello, el objetivo de este trabajo es exponer las diferentes narrativas acerca del sitio que circularon desde principios del siglo $\mathrm{XX}$ a la actualidad cuando comenzaron las primeras expediciones arqueológicas de la Quebrada de Humahuaca (Boman 1991 [1908]). Sin embargo, estas no fueron las únicas narrativas que circularon concernientes a este sitio. Además, ellas se han ido modificando, solapando o adquiriendo diversos grados de legitimación, del mismo modo que los valores y usos del pasado que definían el tipo de vinculación que los distintos actores sociales (comunidades originarias, pobladores locales, elites local y provincial, turistas e investigadores sociales, entre los principales) tuvieron con el sitio. En este sentido, la estructura productiva, la conformación de elites, así como la constitución social y étnica de la Quebrada de Humahuaca fueron claves para comprender las diversas narrativas en pugna desde entonces en Peñas Blancas.

A partir de prospecciones en el sitio entre 2008 y 2012, pudimos observar sus características y su estado de conservación. Solo se realizó la medición de algunos muros, observándose la presencia en superficie de cerámicas pre y postincaicas que coincidirían con las descripciones publicadas por otros arqueólogos que lo visitaron durante el siglo $\mathrm{XX}$ (Nielsen 2001; Palma 1991; Raffino 2007). Pero, además, se observaron algunas de las intervenciones realizadas en el sitio por los pobladores locales, como la reutilización de materiales para la construcción y relocalizaciones de ellos en el mismo sitio para realizar nuevas formas (Figuras 2 y 3 ).

Consideramos que los paisajes siempre se presentan como un escenario cargado de huellas, de memorias y narrativas en tensión. En este sentido, a partir de julio de 2003, cuando la Organización de las Naciones Unidas para la Educación, la Ciencia y la Cultura (UNESCO) incluyó a la Quebrada de Humahuaca en la lista de patrimonio mundial, también se acentuaron las ambigüedades y contradicciones de sentido que responden a diferentes visiones del mundo pertinentes al patrimonio y los comportamientos asociados (Choay 2007). Como establecen Menezes Ferreira y Mujica Sallés (2012), al estudiar la relación entre cultura material y diversidad, la arqueología, así como otras disciplinas 


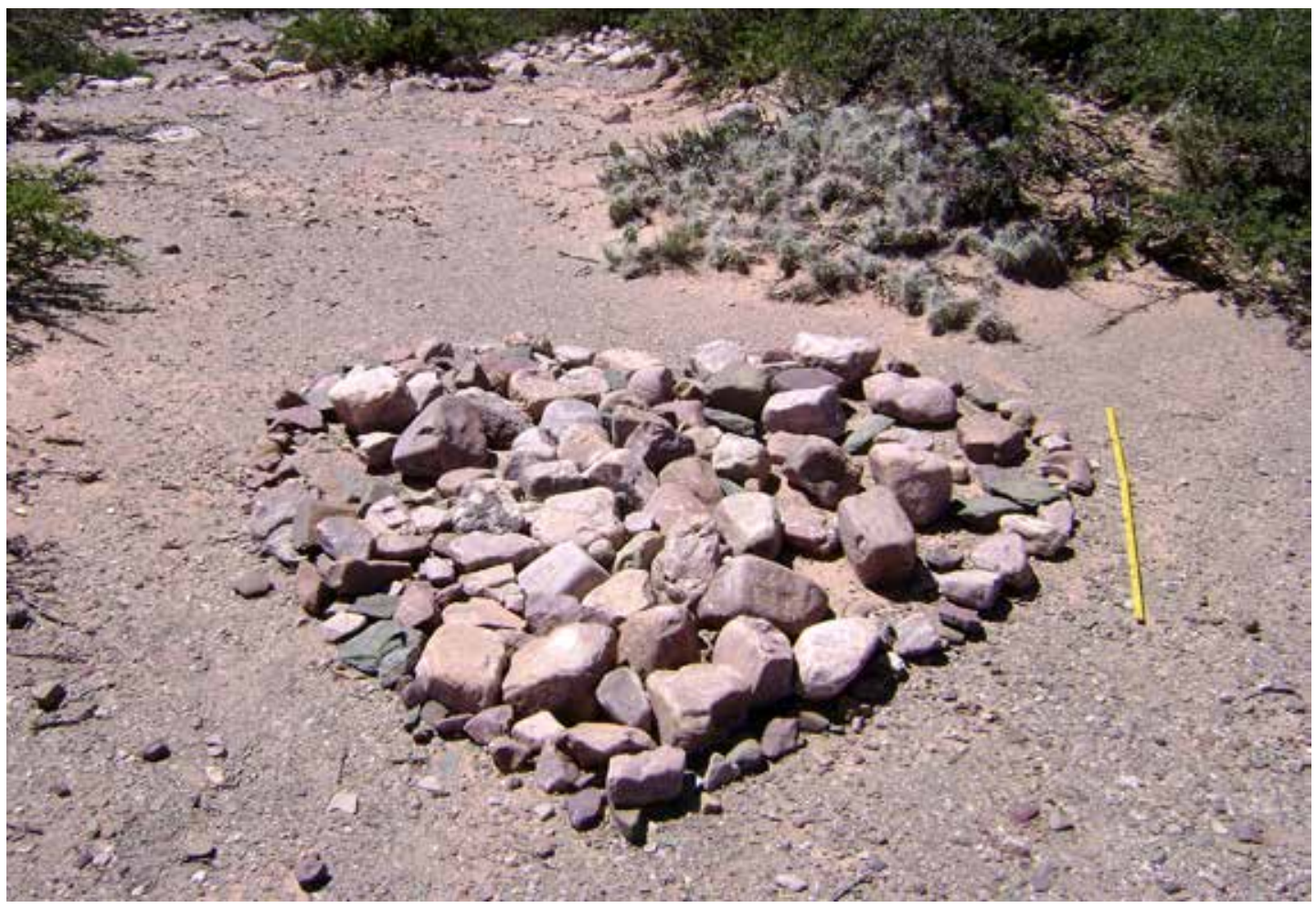

Figura 2. Intervención en el sitio Peñas Blancas, con las rocas del sitio se realizó un corazón. Registrado en 2011. Fotografía de Mariel López.

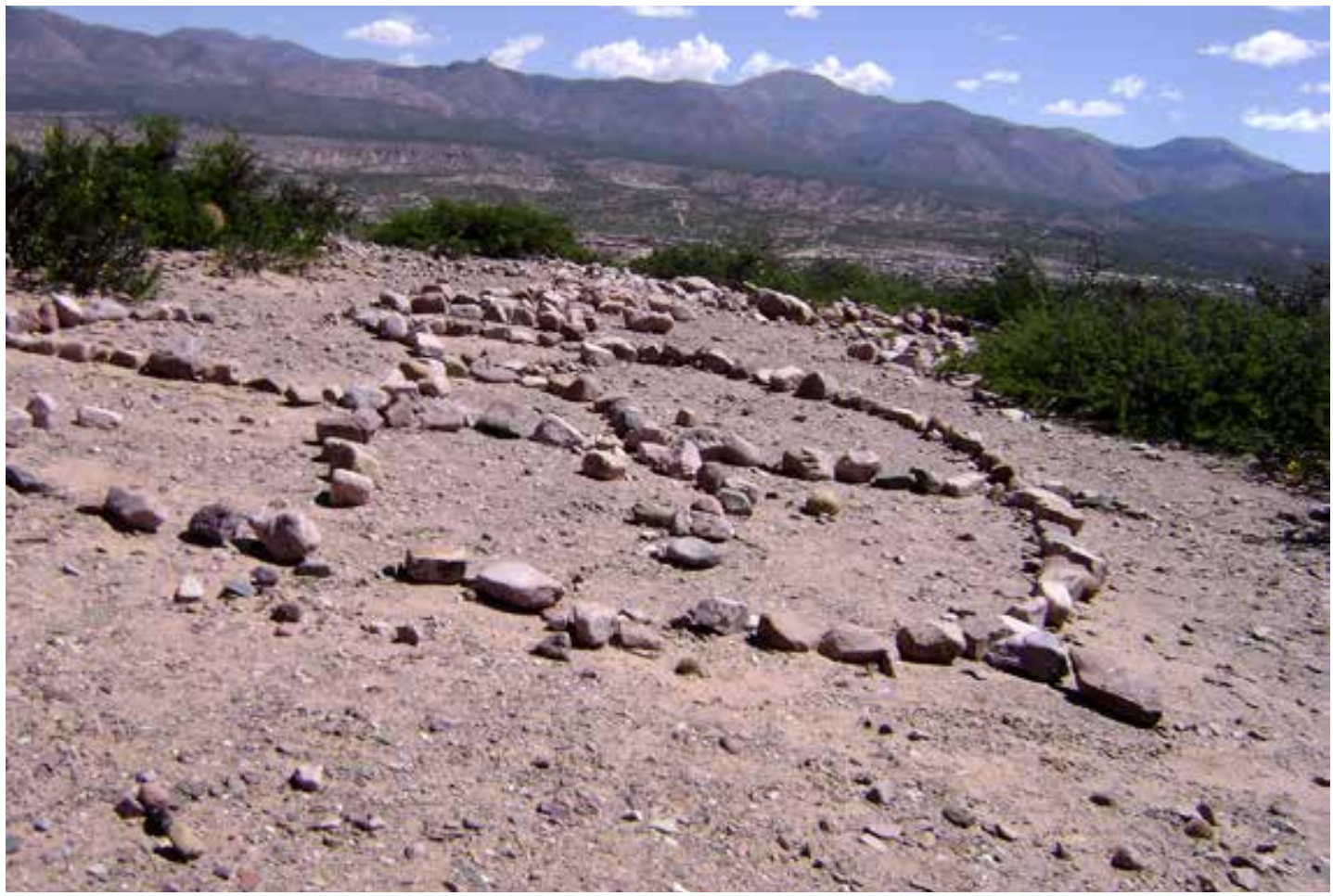

Figura 3. Intervención en el sitio Peñas Blancas, en la forma de "A" de anarquía. Registrado en 2008 y 2011. Fotografía de Mariel López 2011. 
sociales, se vio envuelta necesariamente en las luchas en torno a las representaciones del pasado.

La particularidad de los objetos y los sitios que fueron activados como patrimonio cultural mediante distintos discursos e intervenciones es que ellos pertenecen a un orden material prediscursivo, pero no precultural de la existencia social (Lazzari 2012); o como sostiene Prats (2005), ellos condensan y encarnan una visión del mundo. A su vez, coincidimos con el planteo que sostiene que en los sitios arqueológicos perviven las relaciones coloniales (Fernández-Osco 2010). Ahora bien, es importante señalar que mientras que estos sitios se conocen como "restos arqueológicos" o "sitios históricos", para las comunidades originarias son parte de su vida cotidiana y fuente de memoria. Por ello, también consideramos que los sitios como Peñas Blancas son lugares ligados a la religiosidad y la organización y conciencia política.

Para abordar el objetivo de investigación antes planteado hemos apelado a la complementación de distintos tipos de fuentes y resultados de investigación (Endere y Chaparro 2013; Endere et al. 2013). La metodología planteada contempló, entonces, la recopilación de los antecedentes históricos y de la caracterización socioeconómica de la población para contextualizar la información. Luego se desprendieron ejes de análisis: 1) el relevamiento de los trabajos académicos en el sitio Peñas Blancas; 2) el análisis del marco legal y administrativo del patrimonio cultural en el sitio y en la Quebrada de Humahuaca; 3) relevamiento de la promoción turística de Peñas Blancas; 4) conversaciones, observación participante y entrevistas con diferentes representantes vinculados al sitio.

\section{Peñas Blancas: de ruinas del pasado a patrimonio mundial}

Partimos de una revisión general del contexto de la Quebrada (Mancini 2016), desarrollando aquí la información referida al caso de Peñas Blancas. En cuanto a los trabajos académicos hallamos que desde fines del siglo XIX se menciona reiteradamente el pueblo de Humahuaca en relación con los destrozos encontrados producto de las luchas por la Independencia, en especial a partir de los recorridos de viajeros y naturalistas que partían en expediciones para reconocer las potencialidades productivas del país (Benedetti 2010). En esta literatura, en general, no aparecían muchas menciones ni de ruinas ni de yacimientos prehispánicos, pero el sitio Peñas Blancas ya era conocido: "Humahuaca (...) lugar célebre donde los antiguos indios de Humahuaca han dejado sus rastros, en el Pucará y donde más tarde se estableció la misión Santa Bárbara" (Brackebusch 1990:35 [1883]).

Las primeras investigaciones propiamente arqueológicas que se centraron en la Quebrada de Humahuaca, coincidiendo con el inicio de la arqueología de "campo", concebían al mismo como un lugar extraño, de sociabilidad "premoderna", en donde los investigadores "debían aprender a manejarse diplomáticamente" (Podgorny 2004:154). La mayoría de los estudios acerca de la historia de las investigaciones arqueológicas en la región toman como inicial la expedición de 1901 (Fernández 1982; Fernández Distel 1997; Nielsen 2001; Raffino 2007), dirigida por Nordenskiöld e integrada también por Boman y Von Rosen. Desde entonces, Boman fue considerado como el primer científico en realizar observaciones en las ruinas de la Quebrada (Boman 1991 [1908]). Antes de estas expediciones el conocimiento de la arqueología de la Quebrada era muy escaso y solo se había publicado un trabajo de Ambrosetti de 1901 que planteaba, a partir del análisis de algunos materiales, la influencia "calchaquí" en la zona (Fernández 1982). Además, Boman fue quien primero definió a la Quebrada de Humahuaca como una región arqueológica: “...en el estrecho valle llamado Quebrada de Humahuaca y en las montañas circundantes, vivía un pueblo muy guerrero, los omaguacas, que parece diferente tanto de los diaguitas como de los atacamas". (Boman 1991:19 [1908]). Esta afirmación generó un debate que se llevó adelante en diversos ámbitos, especialmente en el Congreso Internacional de Americanistas, hasta que Ambrosetti reconoció que se trataba de un área diferente (Podgorny 2004; Otero 2013; Mancini 2016). Así se inauguraba la tradición de asimilar territorios con áreas culturales, noción que no sería cuestionada hasta las últimas décadas del siglo XX en la región (Pérez Gollán 1996). De manera análoga, perduró la hipótesis de la escasa antigüedad de las culturas que habitaron el Noroeste Argentino (NOA) que proponía Boman, que llevó a que la arqueología se apoyara en las fuentes de la época de la conquista europea y que no se desarrollara una estratigrafía que permitiera ver los cambios culturales del NOA (Ramundo 2007).

No obstante la poca profundidad temporal asignada a las culturas antiguas, la disciplina 
consideró a los restos del pasado como parte de un pasado extinto y, por tanto, "arqueológicos". Por ello, no se asociaron al patrimonio cultural de las comunidades originarias que actualmente habitan la región (Mancini 2016). En ese marco, y a lo largo del siglo XX, se desarrollaron las principales excavaciones sistemáticas de Peñas Blancas por Gatto en 1931 y 1933 (Gatto 1941), a las que siguieron los trabajos de campo de Márquez Miranda realizados en 1933 y 1944 (Márquez Miranda 1945).

Márquez Miranda mantuvo vigente el influjo de la escuela histórico-cultural predominante de la época. A pesar de ello, a partir de la obra de Bennett (1948) y de la sistematización del conocimiento de los materiales arqueológicos de la región, comenzó a resquebrajarse el modelo de la exégesis de las fuentes históricas (González 1985; Olivera 1994; Nielsen 2001), acentuándose el interés por la cronología de las culturas quebradeñas. Sumado a ello, comenzó una etapa de modernización de la arqueología impulsada, especialmente, por Alberto Rex González, quien impuso en el NOA la excavación estratigráfica (Fernández 1982; González 1985; Olivera 1994; Nielsen 2001).

Pese a haber sido muy tempranamente detectado en la arqueología de la región, Peñas Blancas no fue excavado en esta nueva etapa y solo fue visitado en prospecciones de fines del siglo XX y mencionado por la presencia incaica en él a partir de rasgos arquitectónicos (Palma 1991; Raffino 2007; Nielsen 2001)

En cuanto al análisis del marco legal, desde principios del siglo XX los académicos y expertos generaron un discurso respecto del patrimonio cultural que fue canalizado e institucionalizado por medio de organismos del Estado y normativas (ver Tabla 1). Si bien en una primera etapa hubo abundancia de investigaciones en las "ruinas prehispánicas" hubo una mayor atención de la necesidad de protección en los edificios correspondientes a la colonia o a otros períodos posteriores de la historia nacional. De hecho, en la década de 1930 las ruinas y los yacimientos quedaron por detrás del interés de la arquitectura histórica de la Colonia o las primeras décadas de la independencia (Mancini 2016). En Humahuaca esto se tradujo en legislación específica. Así, diversas capillas de la Quebrada se declararon Monumentos Históricos Nacionales (MHN), se restauraron algunos edificios del pueblo de Humahuaca como la iglesia y el cabildo y se construyó el Monumento de la Independencia (Ley Nacional $\mathrm{N}^{\circ} 11.383 / 1933$ ).

En cuanto al sitio Peñas Blancas, este quedó bajo dominio del Estado argentino a partir de la Ley Nacional $N^{\circ} 9.080 / 1913$ que indicaba, en términos generales, que las ruinas y yacimientos arqueológicos de interés científico eran de dominio público y debían ser investigados por personas idóneas, con autorización del Museo Etnográfico, del Museo de Historia Natural (ambos de Buenos Aires) y, luego de la reglamentación de la ley en 1921, del Museo de Ciencias Naturales de la Plata. Además, este sitio fue reconocido como parte del Parque Arqueológico Coctaca (Ley Provincial $\mathrm{N}^{\circ}$ 4126/1984). En el 2000 la Comisión Nacional de Museos, Monumentos y Lugares Históricos (CNMMyLH) seleccionó cuatro sitios de la región para ser declarados MHN: Coctaca, Los Amarillos, La Huerta y el Pucara de Tilcara. A pesar de tener características suficientes para ser considerado en esta lista de sitios destacados de la Quebrada de Humahuaca, Peñas Blancas no estuvo entre los elegidos. Según se detalló en la declaratoria como MHN, Coctaca se eligió por ser complejo agrícola prehispánico; Los Amarillos, por ser el asentamiento residencial prehispánico más extenso; La Huerta, por ser uno de los asentamientos omaguacas de mayor importancia durante la dominación inka (por su kallanka y la ocupación posthispana); el Pucara de Tilcara, por su extensa ocupación, donde residiera Viltipoco, quien organizó la última rebelión en la Quebrada en 1595. Pero, además, este último sitio se destacó por ser trabajado por Ambrosetti y Debenedetti y luego restaurado por Casanova (Decreto 1002/2000). Finalmente, con la declaratoria de Paisaje Cultural Patrimonio Mundial de la UNESCO (2003), como todos los sitios de la Quebrada, Peñas Blancas quedó reconocido como patrimonio cultural.

Además, el fenómeno turístico se produce en una continuidad entre el núcleo emisor -aquel lugar donde el turista vive-, el desplazamiento de ese turista y el núcleo receptor -lugar donde el turista llega y permanece- (Barretto 2003). En este desplazamiento ocurren ciertas acciones y relaciones sociales que comenzaron a ser abordadas por las ciencias sociales paulatinamente desde la década de 1970, hasta convertirse en un campo académico (Smith 1980, 1992; Nash y Smith 1991; Barretto 2003). A su vez, una parte del turismo tiene como eje procurar la experiencia de lo diferente, lo exótico 


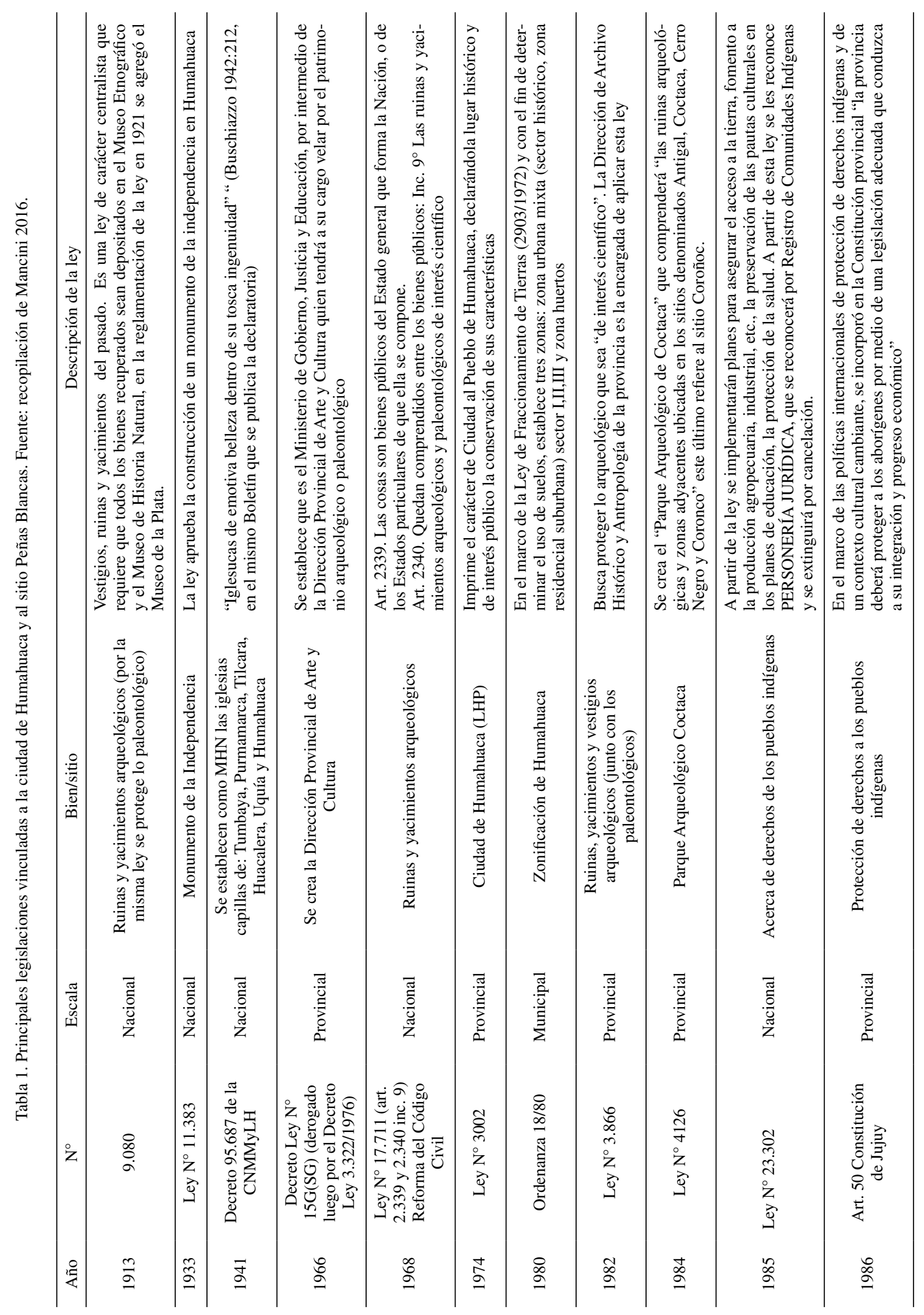




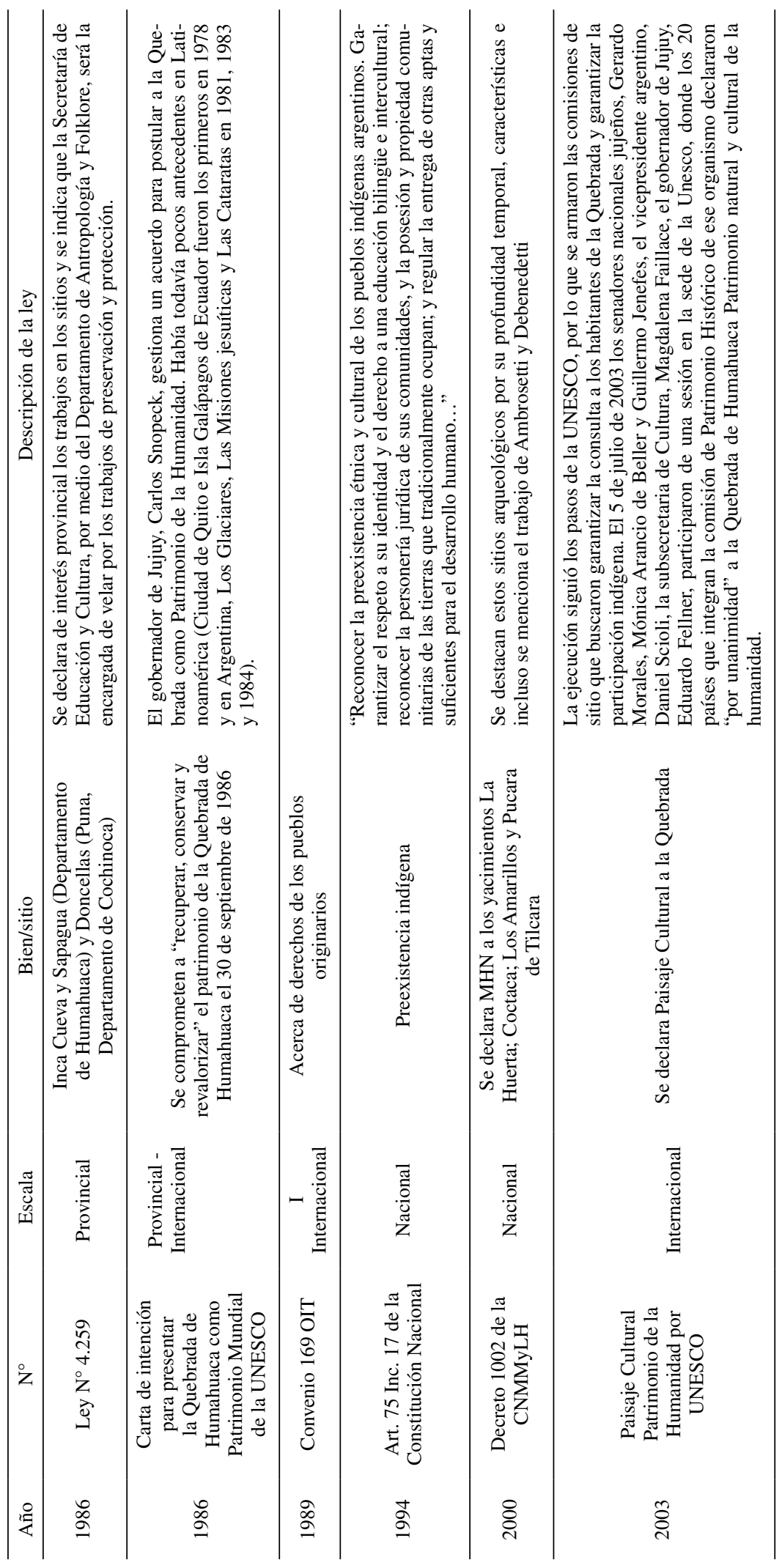


o la otredad y, en este sentido, el turismo puede pensarse como una relación interétnica. Esta relación no es igualitaria, en especial en el caso del turismo que visita sectores marginales al capitalismo occidental como la Quebrada de Humahuaca. En este sentido, entre otros de los impactos del turismo, se ha señalado la emergencia de "nuevas etnicidades", nuevos sujetos sociales, nuevas comunidades que, siendo subalternos, intentan redefinirse y hablar por sí mismos ante los efectos del turismo global (Grünewald 2003).

Para el análisis del discurso del turismo, consideramos guías de promoción turística desde 1929, cuando el Automóvil Club Argentino (ACA) publicó su primera revista con imágenes de la región, hasta el 2010. Además se relevaron otras revistas nacionales y provinciales que fueron representativas de la promoción turística de la Quebrada de Humahuaca a lo largo del siglo XX e, incluso, comienzos del siglo XXI (Tabla 2).

El turismo en la Quebrada de Humahuaca se comenzó a desarrollar con la llegada del ferrocarril que se puso en marcha a principios del siglo XX atravesándola de norte a sur. En un primer momento, los "veraneantes" provenientes de las elites de las capitales provinciales del NOA llegaban atraídos por el clima y el ambiente sin paludismo (Janoschka 2003; Troncoso 2009). Ellos se veían a sí mismos como los benefactores de los quebradeños, promoviendo el turismo a partir de la conservación de patrimonio histórico y el pintoresquismo local, aunque su interés por las costumbres locales era percibido por los quebradeños como una intromisión (Mancini 2016). En esta primera etapa, las guías turísticas mencionan el pasado prehispánicos, las raíces "primitivas" y la historia colonial como atractivos de la Quebrada, pero no incluyen los sitios arqueológicos en sus itinerarios (ver Tabla 2). Con el peronismo comenzó un nuevo tipo de turismo, masificado y vinculado a las mejoras de los derechos laborales (Janoschka 2003). Así, para la década de 1960, el turismo se transformó en nueva una opción en la Quebrada, incluso como destino de invierno y ligada a la idea de desarrollismo de la época. En la promoción turística en las guías, los sitios arqueológicos que hasta la década de 1950 prácticamente no aparecían mencionados, fueron paulatinamente recibiendo mayor atención, en especial el Pucara de Tilcara que en 1948 fue parcialmente reconstruido y habilitado para ser visitado (Mancini y Tommei 2012; Mancini 2016). En ese contexto, el sitio Peñas
Blancas pocas veces era mencionado. En general, cuando se hablaba de ruinas o yacimientos, se mencionaba al Pucara de Tilcara y hacia la década de 1960 Tilcara se posicionaba como "capital arqueológica” en relación con el conocimiento que se iba adquiriendo del sitio arqueológico, que había sido cedido a la UBA y también por su relación con el turismo (Mancini 2016).

En la década de 1990, Jujuy aún se encontraba en situación crítica desde la última dictadura militar (1976-1983), con un alto desempleo y dependiente del asistencialismo del Estado (Reboratti et al. 2003); en ese contexto el turismo comenzó a plantearse como una alternativa de desarrollo local ante la crisis económica. De hecho, desde 1983, la provincia promovió diversos incentivos al turismo, incluida la patrimonialización ante la UNESCO, cuya primera tentativa fue la Carta de Intención entre el Gobernador de Jujuy y el representante de la UNESCO firmada en 1986 (Tabla 1). De este modo, desde el 2000 el turismo se multiplicó exponencialmente, entre otras causas por la devaluación de la moneda nacional y, desde 2003, por la declaratoria de UNESCO. Las guías en esta etapa siempre incorporan referencias a los sitios arqueológicos, muchas veces junto con la labor de los arqueólogos, en especial en el caso del Pucara de Tilcara.

En ese marco, la construcción de los atractivos de la Quebrada desde el discurso de la promoción turística atravesó notables desplazamientos de interés en el tiempo. Por ejemplo, las luchas de la independencia o las actividades mineras e industriales fueron perdiendo importancia mientras que el valor patrimonial de los pueblos e iglesias, como los paisajes coloridos, las fiestas y el pintoresquismo de lo nativo fueron adquiriéndola a medida que se acercaba el siglo XXI. Del mismo modo, el itinerario propuesto para la Quebrada de Humahuaca no ha sido siempre el mismo. Pero algunas ideas que se formaron desde el comienzo de su promoción turística cobraron cada vez más fuerza hasta convertirse en imágenes representativas: 1) el eje de la RN9; 2) la policromía del paisaje; 3 ) el tiempo detenido o 4) el viaje al pasado (Mancini y Tommei 2012; Mancini 2016). En este contexto general, con el aumento del turismo la oferta turística de Peñas Blancas "Yacimiento Arqueológico" también creció (ver Tabla 2). No obstante, el paseo que se oferta incluye generalmente el ascenso hasta un altar a la Virgen de la Medalla Milagrosa y un mirador, y no realmente al sitio ${ }^{1}$. 


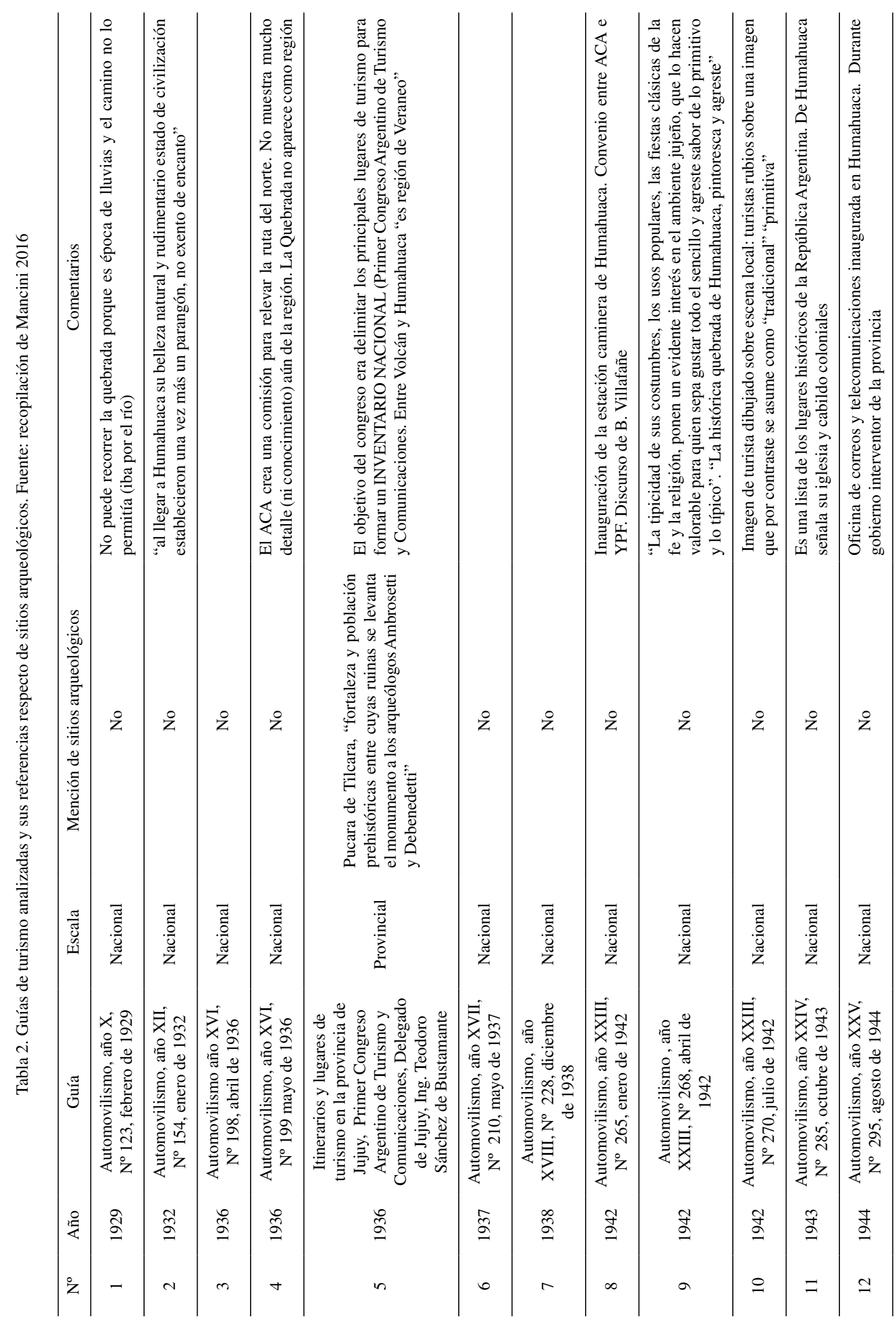




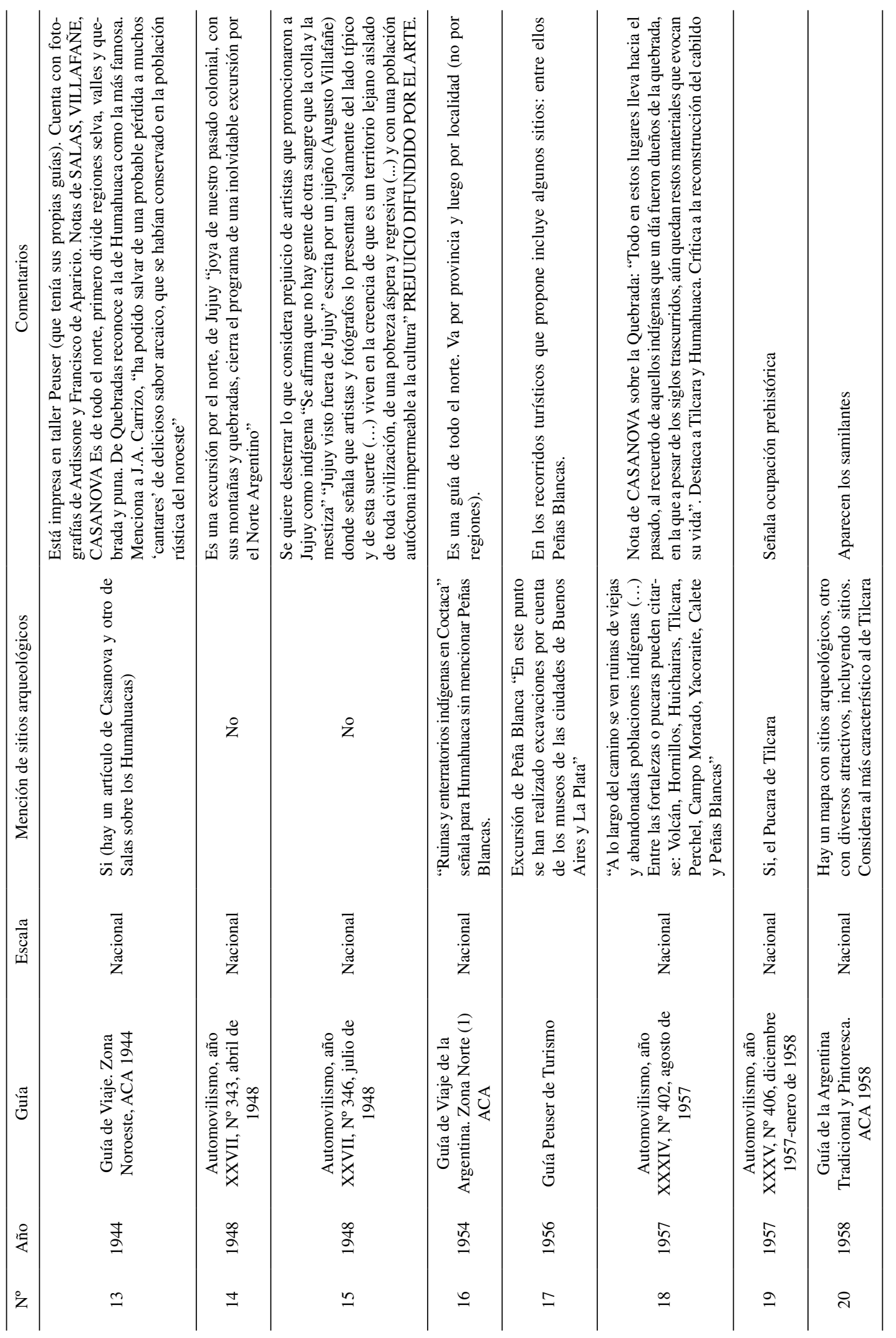




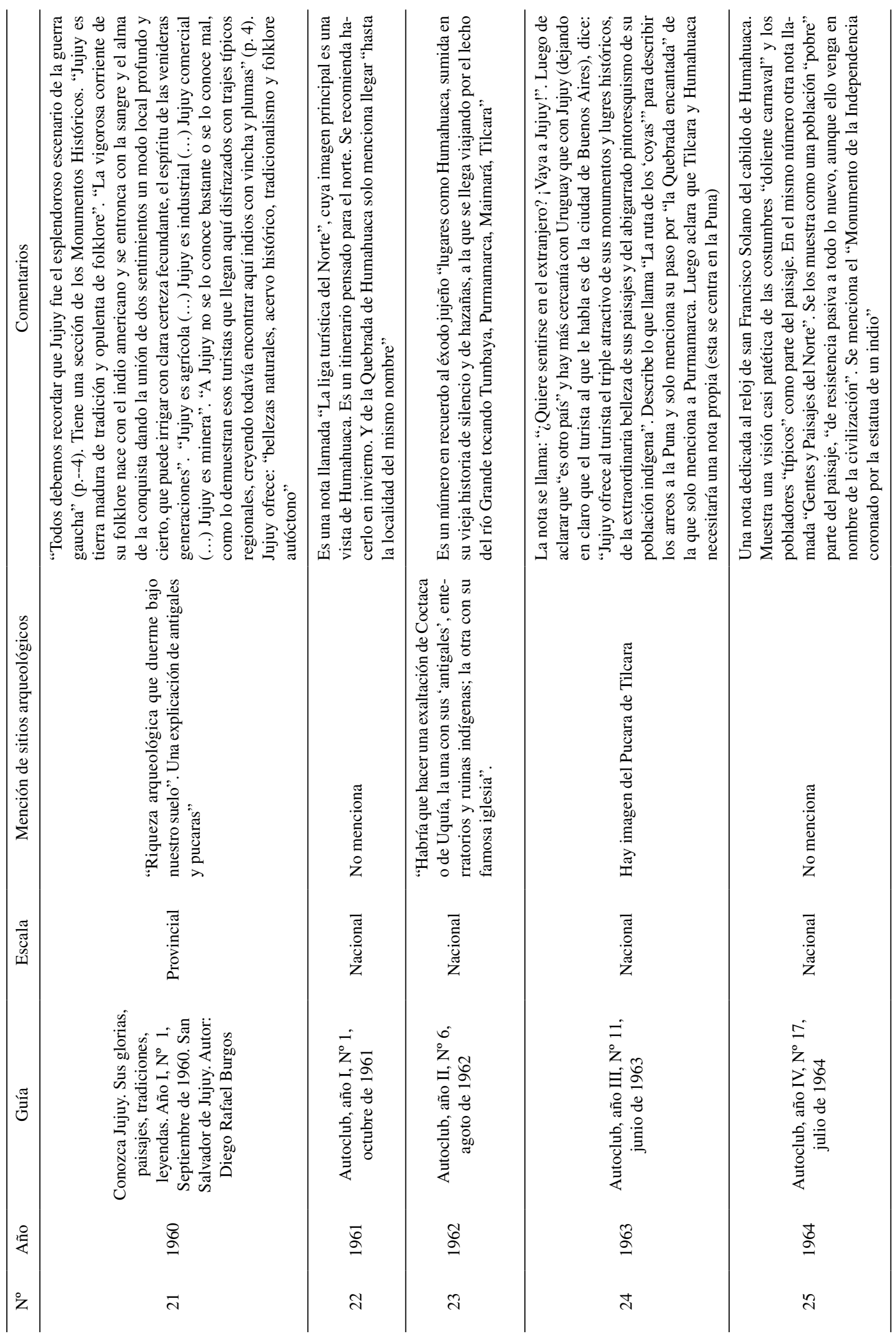




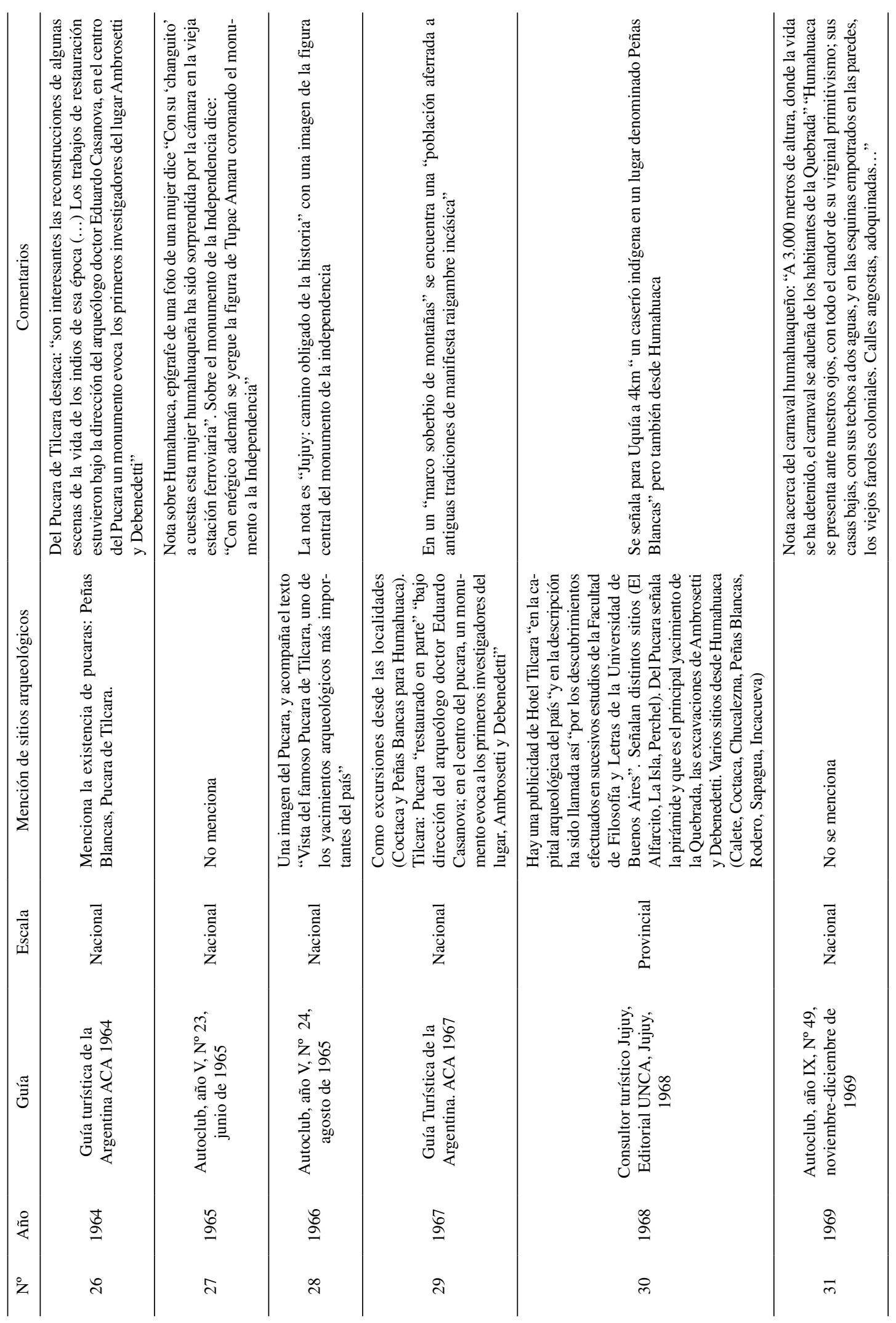




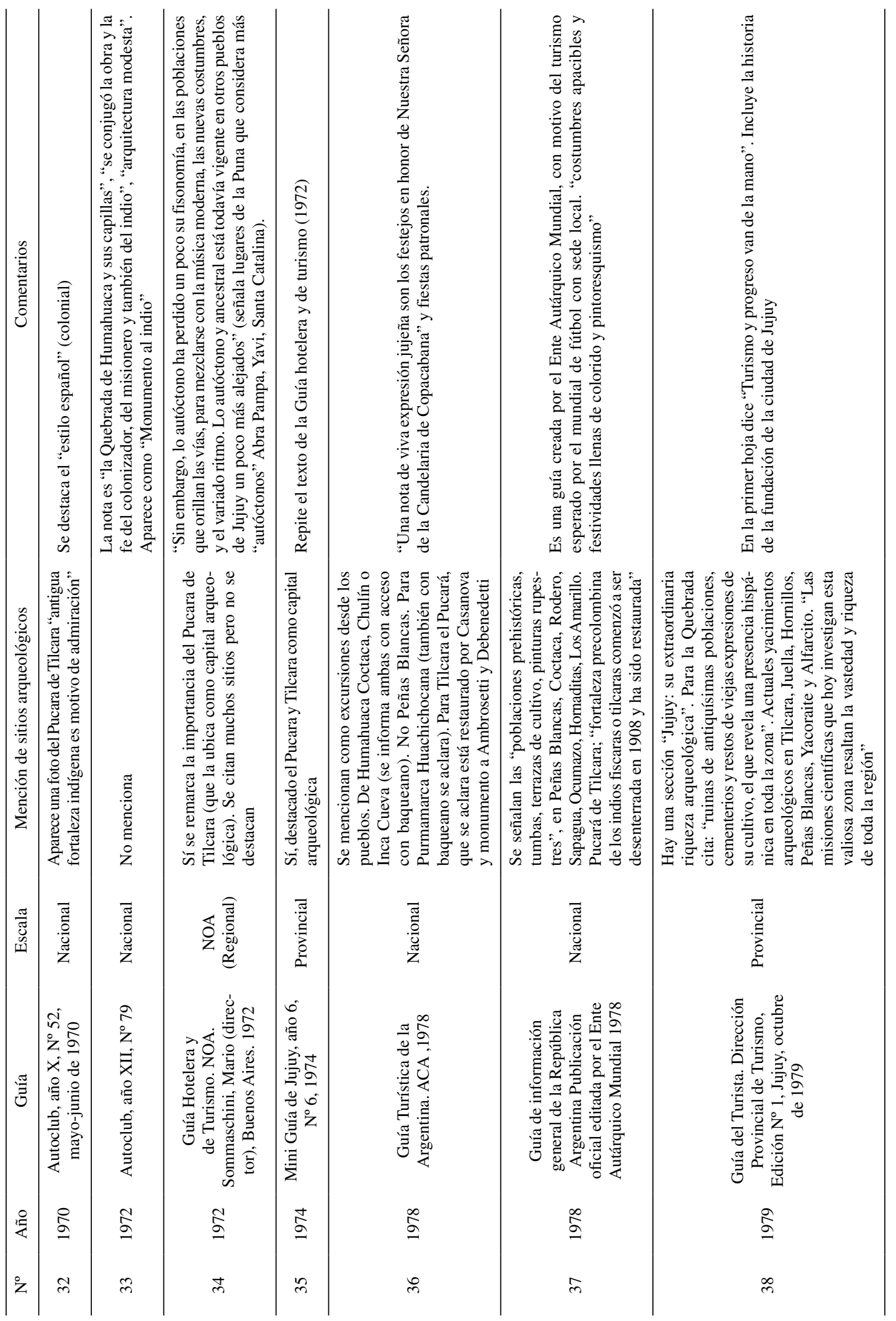




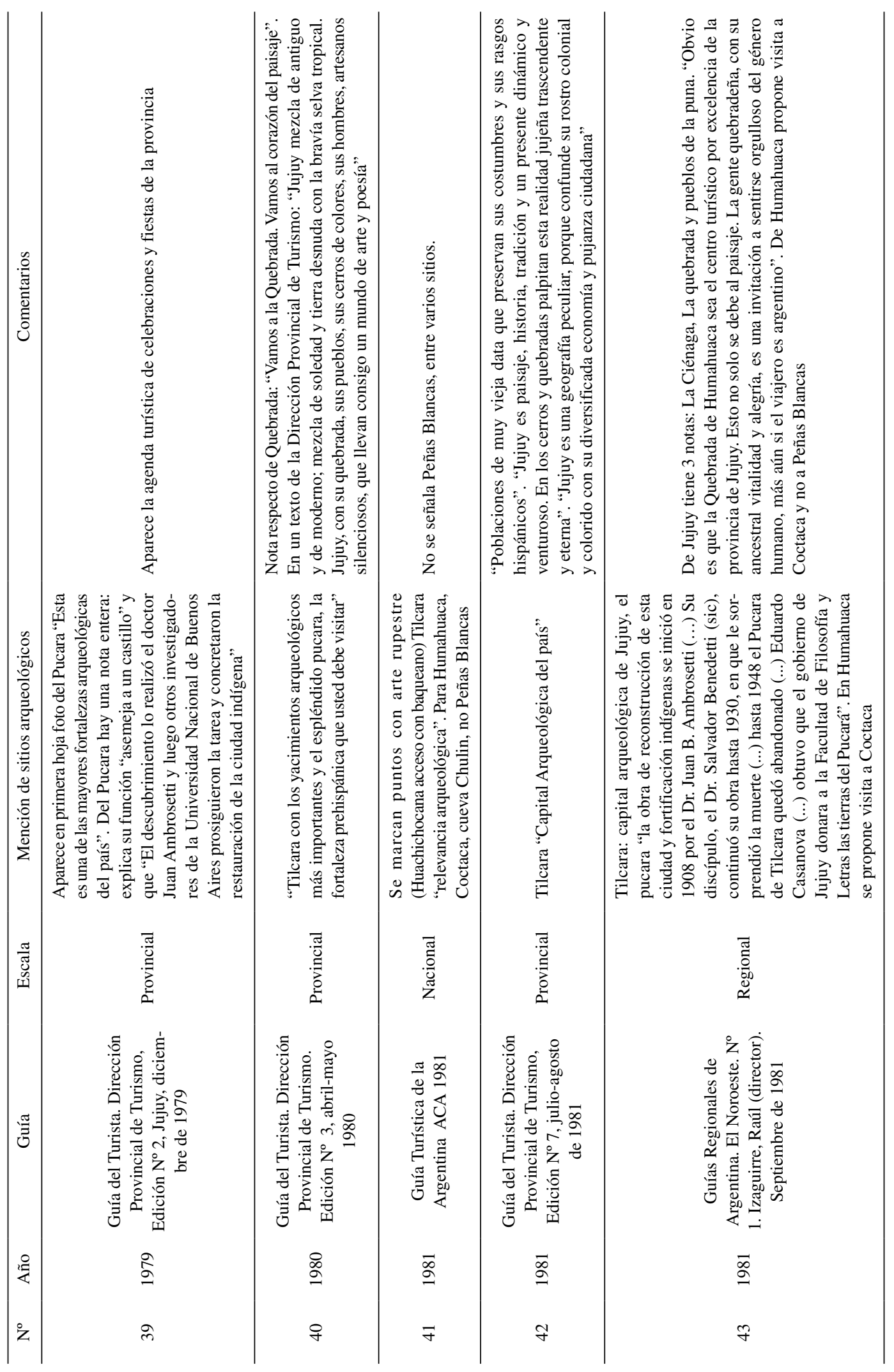




\begin{tabular}{|c|c|c|c|c|c|}
\hline & 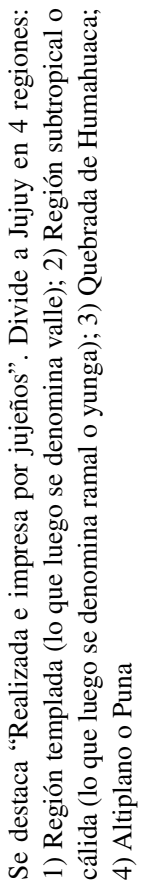 & 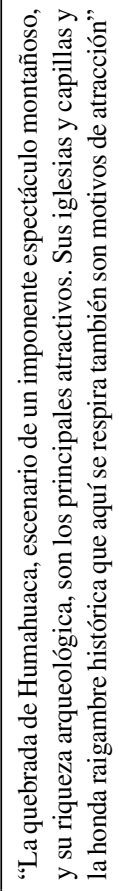 & 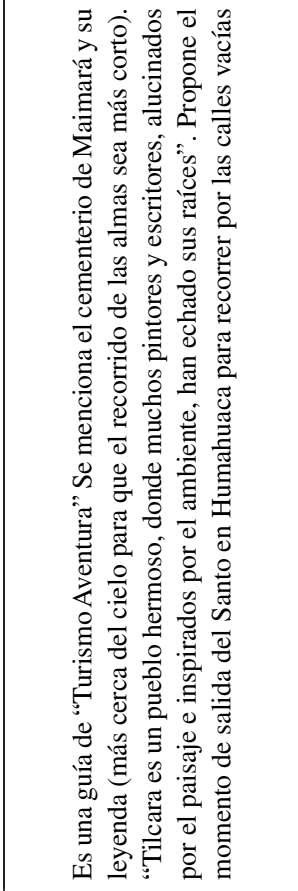 & 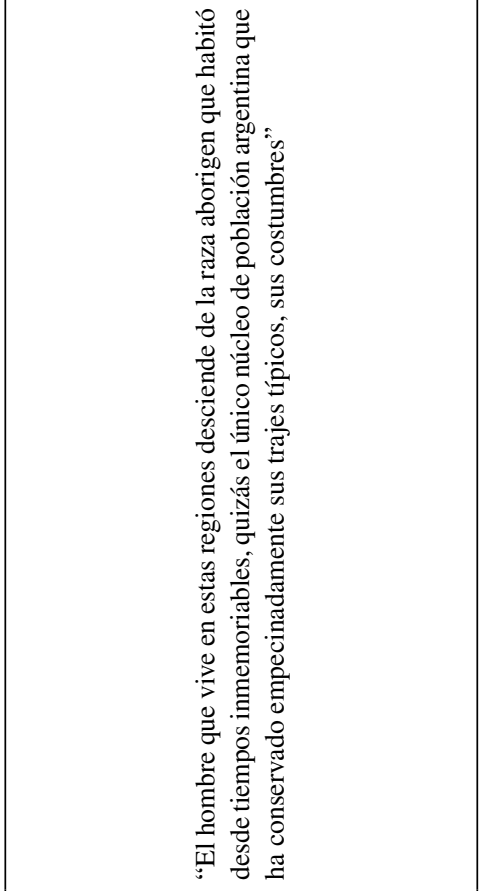 & 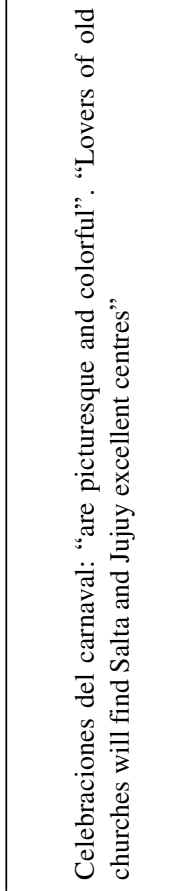 \\
\hline & 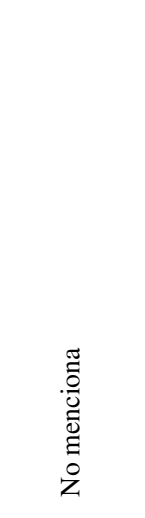 & 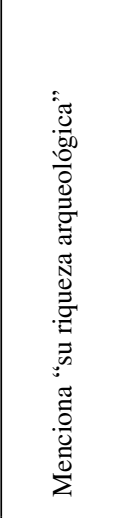 & 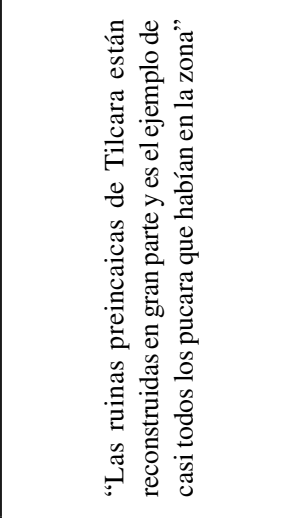 & 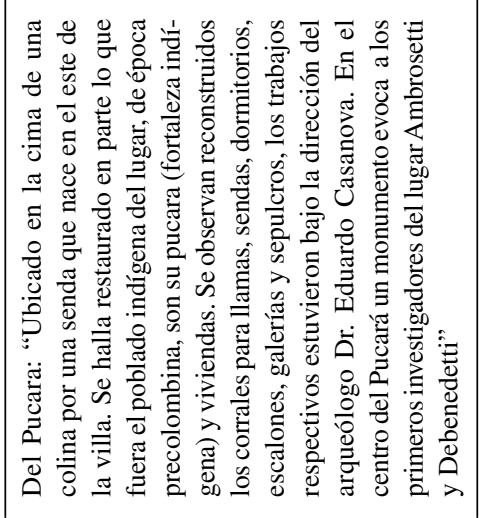 & 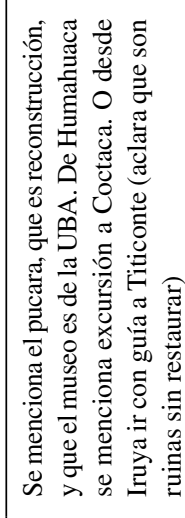 \\
\hline & 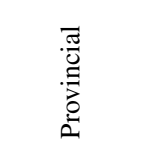 & $\begin{array}{l}\bar{\Xi} \\
\overline{0} \\
\overline{\tilde{Z}} \\
z\end{array}$ & 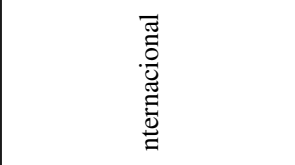 & 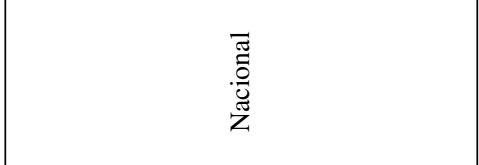 & 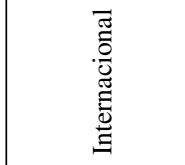 \\
\hline త్ర్ & 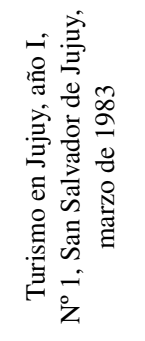 & 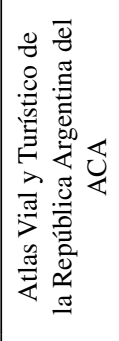 & 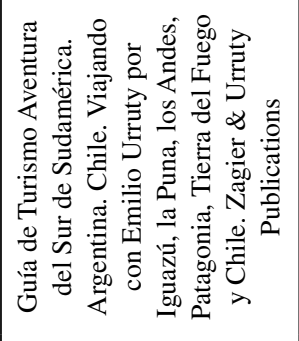 & 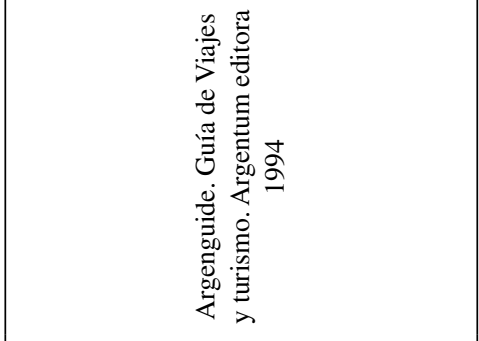 & 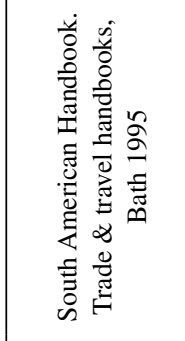 \\
\hline 要 & $\begin{array}{l}\mathscr{\infty} \\
\stackrel{\Omega}{\Omega}\end{array}$ & $\stackrel{\mathscr{O}}{\stackrel{\sigma}{9}}$ & گૂ & $\stackrel{+}{\sigma}$ & $\stackrel{\swarrow}{\sigma}$ \\
\hline iz & 寸 & r & f & f & $\stackrel{\infty}{+}$ \\
\hline
\end{tabular}




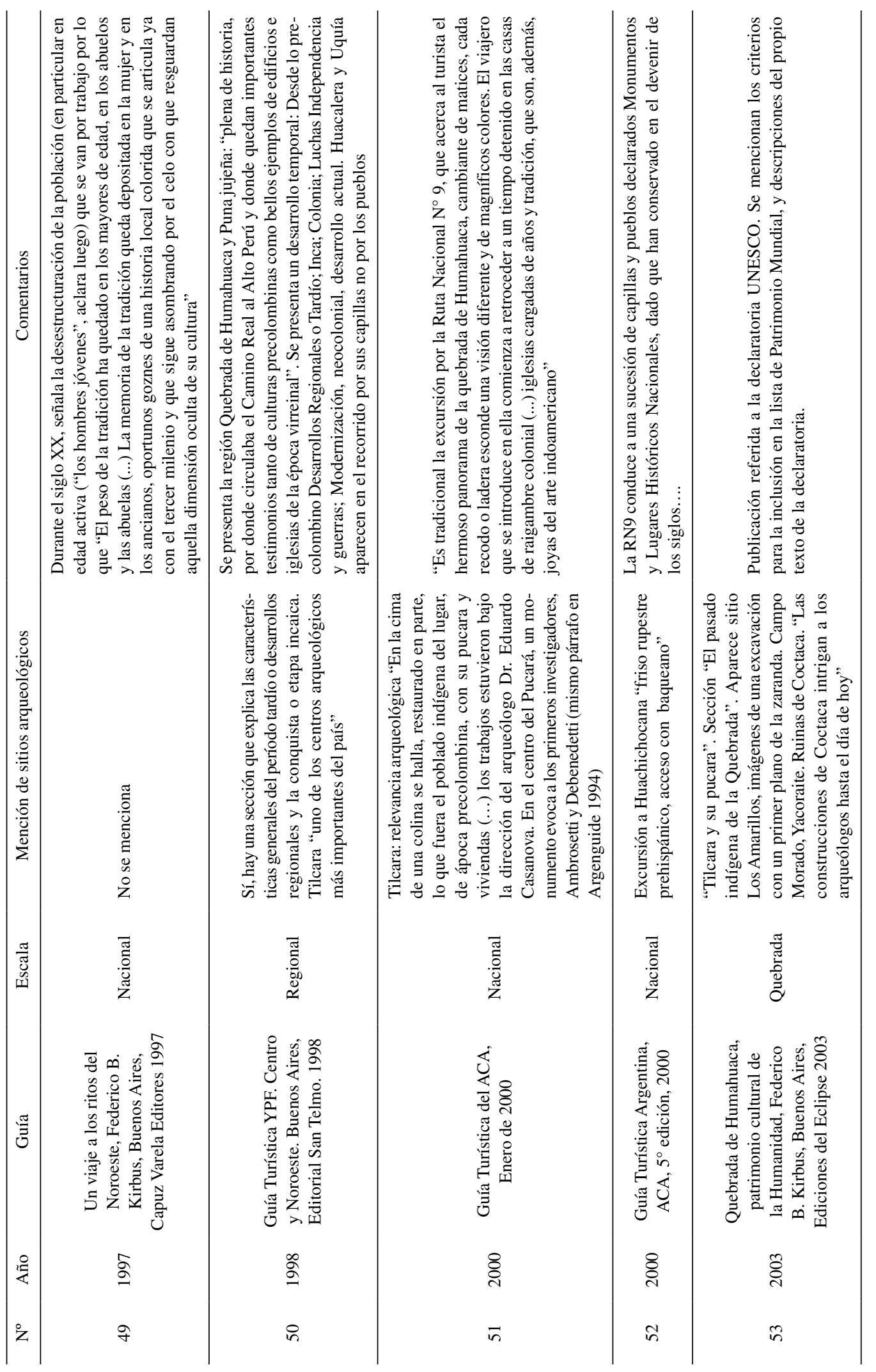




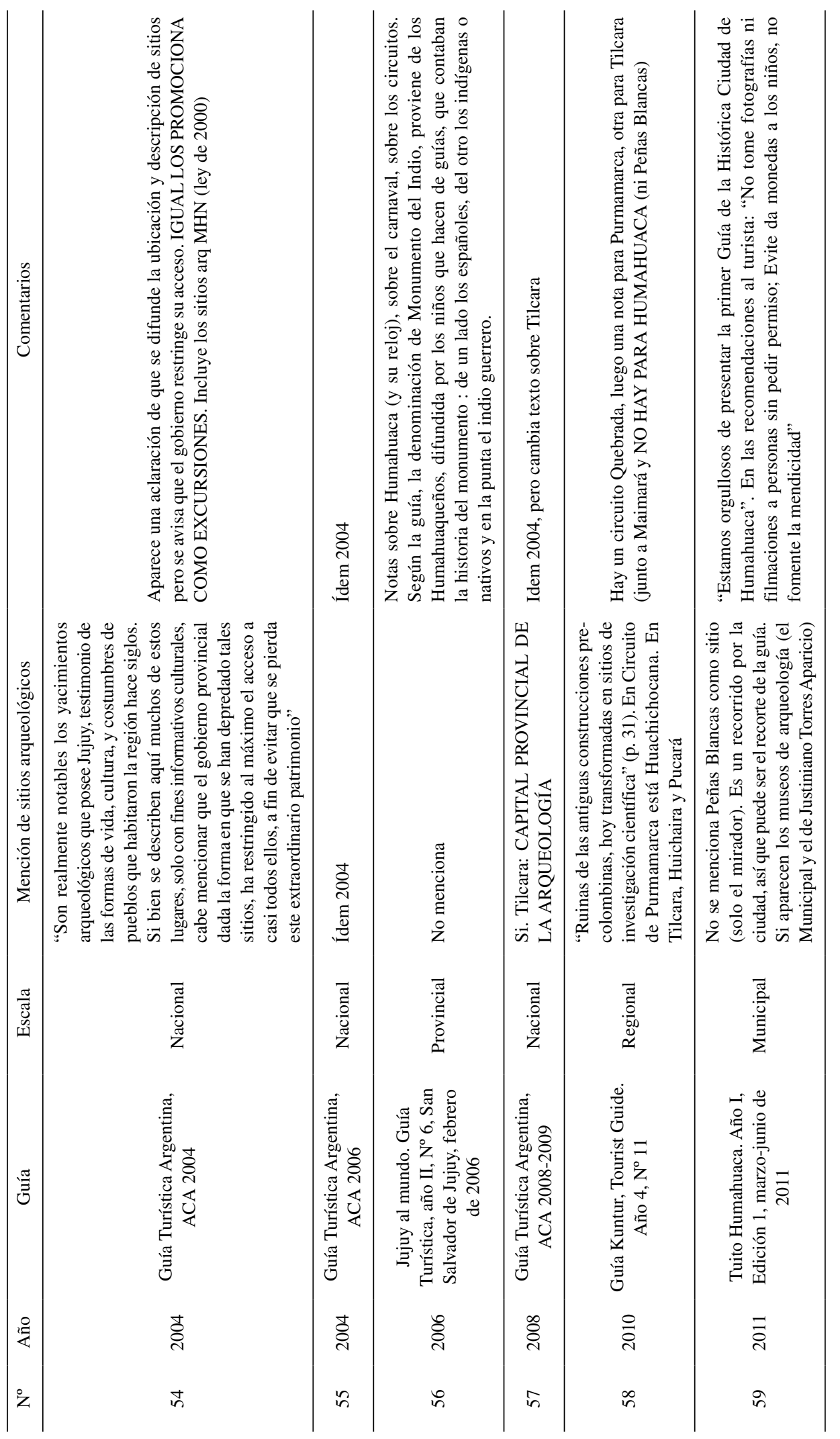


Por otra parte, en la última década gran parte de sus pobladores han comenzado a reivindicar su pertenencia a los pueblos originarios. Este autorreconocimiento fue posible por su organización a nivel local, pero también internacional, a lo que le fueron sucediendo los diversos reconocimientos de sus derechos. Además, observamos que las comunidades de la región han comenzado a reivindicar el acceso a la tierra bajo el reclamo de territorio (López et al. 2016; Mancini 2016). De este modo, mientras que las comunidades originarias toman el concepto de territorio, que incluye al sitio arqueológico y su cultura material, en pos de sus reclamos o reivindicaciones, desde la academia se reconstruye el pasado (material o inmaterial) y se exhibe desde el presente como aquello que merece ser conocido, destacado y estudiado. Todo ello es parte de lo que connota el concepto de patrimonio cultural y constituye lo que se presenta como el legado que identifica a una comunidad. En ese contexto, los sitios arqueológicos de la Quebrada de Humahuaca a principios del siglo XX eran excavados y los restos materiales recuperados eran trasladados a museos alejados del lugar. En cambio, a principios del siglo XXI han comenzado a ser disputados abiertamente por las comunidades originarias, a tal punto que además de las autorizaciones de los organismos del Estado hoy es necesario obtener el consentimiento previo de las comunidades reconocidas para realizar una investigación en sus territorios (López et al. 2016; Mancini 2016).

Entonces, para el caso específico de Peñas Blancas, hemos analizado las entrevistas formales realizadas a pobladores de la Quebrada de Humahuaca, a profesionales y funcionarios de la Secretaría de Cultura de la provincia, así como entrevistas informales a colegas y distintos pobladores durante los trabajos de campo entre 2008 y 2012 (ver Tabla 3).

\section{Narrativas disputadas sobre Peñas Blancas}

De acuerdo con el trabajo realizado existen al menos dos grandes grupos de narrativas: lo que denominamos aquí DPA, compuesto por la voz de los arqueólogos, la elite jujeña y las autoridades (municipales, e instituciones estatales como la escuela y la policía), y otros discursos no sistematizados compuestos por la voz de los pobladores locales, originarios o no. El discurso autorizado comenzó a pergeñarse cuando a fines del siglo XIX la población originaria se encontraba semiproletarizada, con una economía campesina de autoabastecimiento combinada con el trabajo en las haciendas y, más adelante en el siglo XX, con el trabajo en la industria azucarera y tabacalera. Desde entonces, la nueva elite arrendataria empezó un trabajo de legitimación de su dominación. Para ello se presentaron como originarios y naturales herederos de la tierra, por su vinculación con los héroes de la Independencia en oposición a la "construcción de un antagonista externo, los bolivianos" (Karasik 1994:43). Esto se produjo, especialmente, en las primeras décadas del siglo XX, cuando se consagró la fundación de la historia jujeña en las Guerras de la Independencia, a la vez que se desvanecía la raíz indígena (y sus restos materiales) de las poblaciones rurales contemporáneas ${ }^{1}$.

La antropología y la arqueología, entre otras disciplinas, contribuyeron a ese proceso al apropiarse de aquellos lugares devenidos en "sitios arqueológicos", ya que consideraban que no había herederos de aquellos restos materiales (Karasik 1994; Otero 2013; Mancini 2016). Aunque Peñas Blancas había sido mencionado por varios autores, fue Gatto el primero en realizar excavaciones consideradas científicas. En su trabajo advierte que el sitio se encontraba derruido, "ya sea por la acción del tiempo transcurrido desde su abandono por el indígena, ya por los 'antigüeros' que nunca dejan de andar buscando alguna olla repleta de 'quintos' o de algún tapado con riquísimas 'joyas de los incas"” (Gatto 1941:132), No obstante, su hipótesis fue que hubo una comisión extranjera que se llevó gran cantidad de vestigios como, por ejemplo, las que dirigía Schuel, que de hecho estuvo en Peñas Blancas en la década de 1930 (Fernández Distel 1997). Como parte de la visión de la época, Gatto consideraba a los locales "huaqueros" que perseguían la fantasía de enriquecerse, mientras que los científicos y coleccionistas realizaban trabajos arduos y económicamente desinteresados (aunque el resultado fuera el mismo sitio derruido).

Así, las narrativas provenientes de la ciencia sirvieron a la elite local para componer un pasado indígena heroico pero extinto (Rebaudi Basavilbaso 1935; Casanova 1936). Estos discursos se insertaban en el nacionalismo que se imponía de variadas formas como parte del DPA y que, entre otras cosas, anclaba la identidad a la tierra y lo que surge de ella. De este modo, las poblaciones nativas se convertían en un "objeto" de atracción y estudio para 


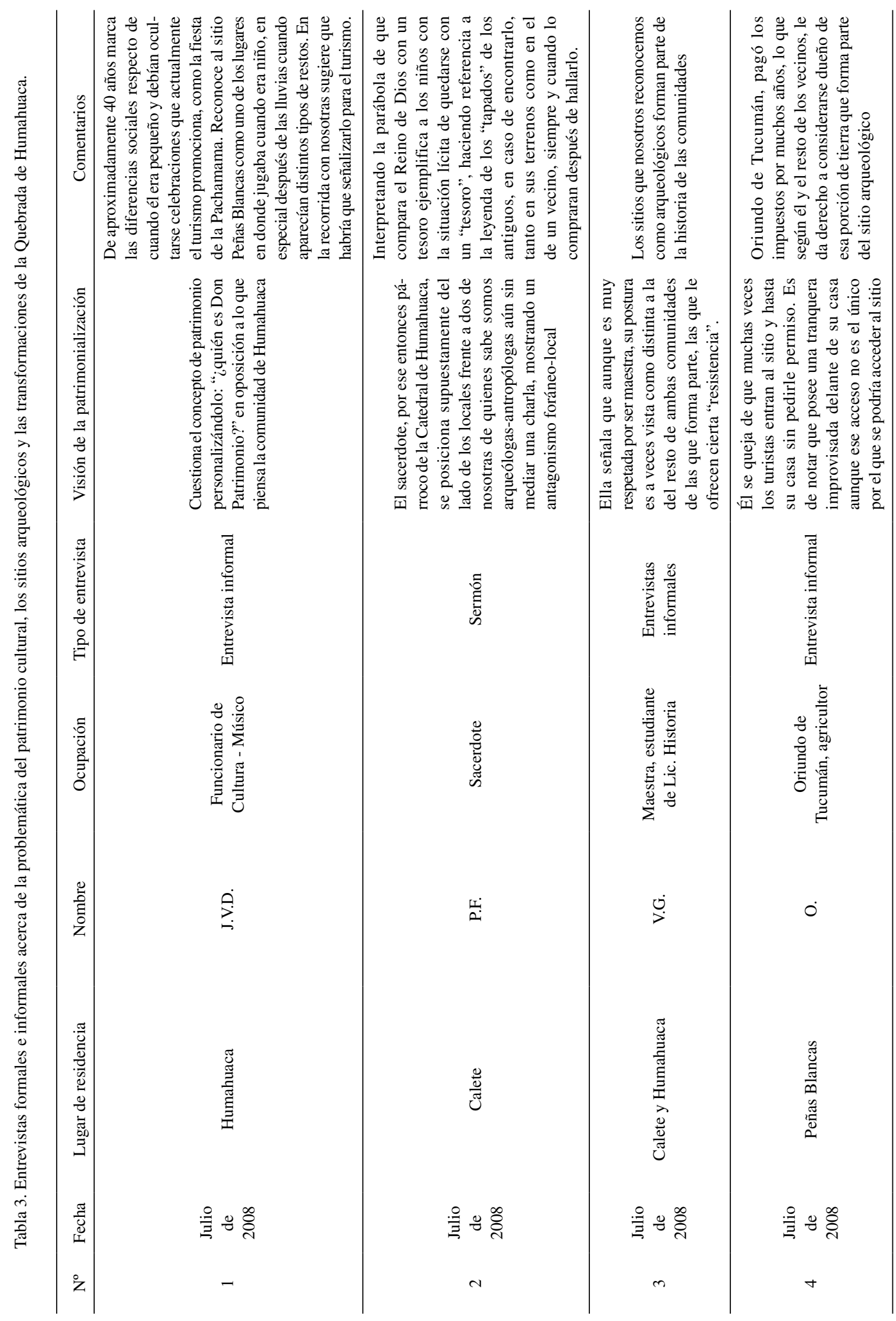




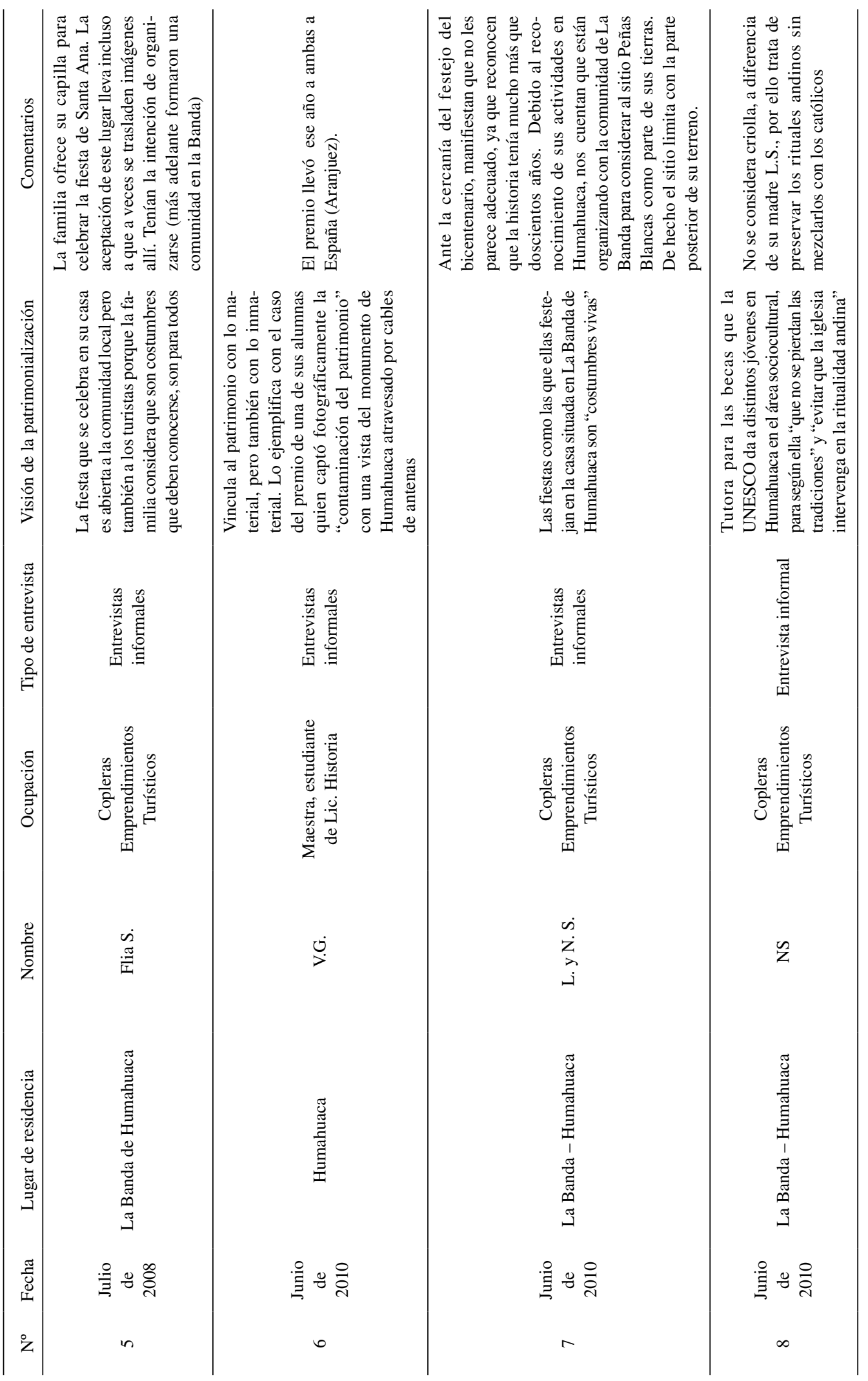




\begin{tabular}{|c|c|c|c|c|c|c|}
\hline & 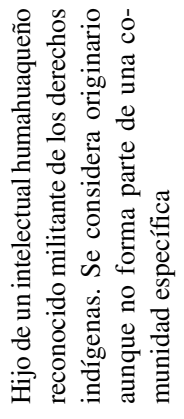 & 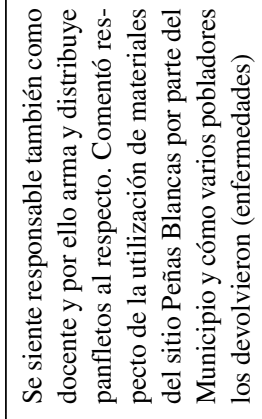 & 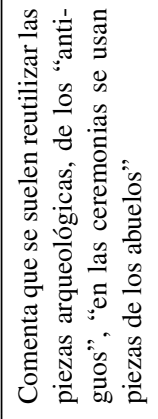 & 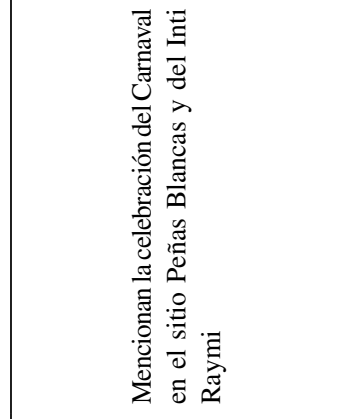 & 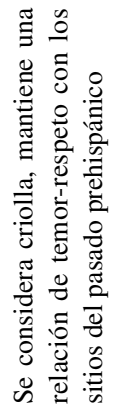 & 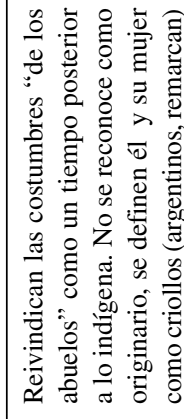 \\
\hline 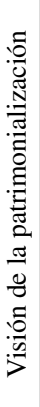 & 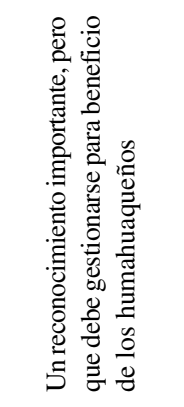 & 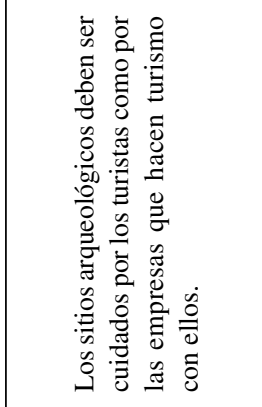 & & 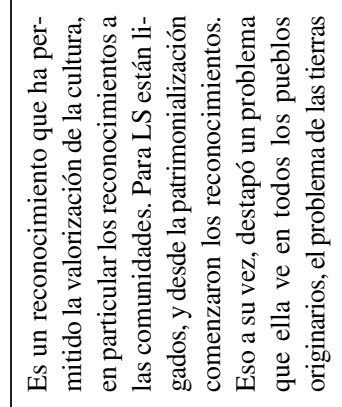 & 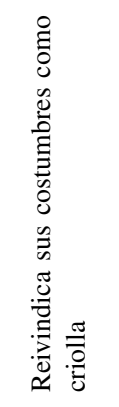 & 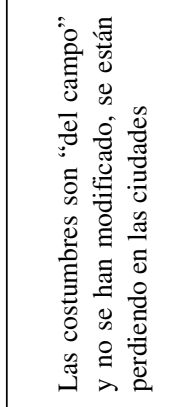 \\
\hline 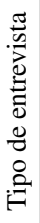 & 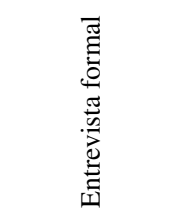 & 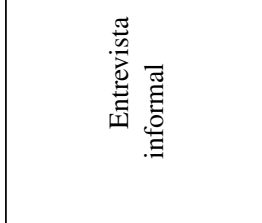 & 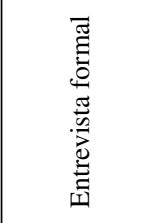 & 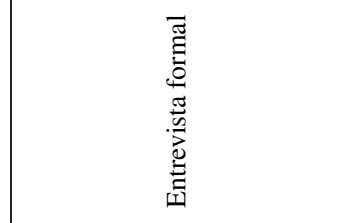 & 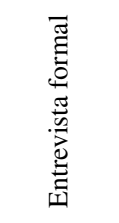 & 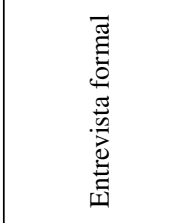 \\
\hline & 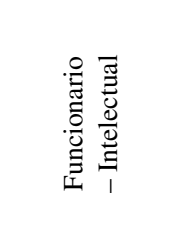 & 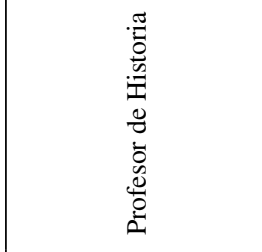 & 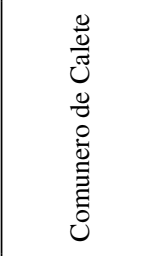 & 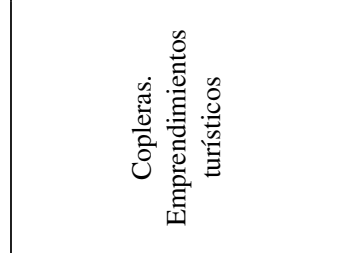 & 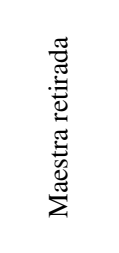 & 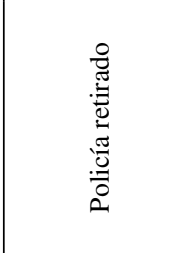 \\
\hline $\begin{array}{l}\text { D̆ } \\
\text { है } \\
\text { Zे }\end{array}$ & $\dot{n}$ & $\begin{array}{l}\overrightarrow{1} \\
\dot{0} \\
\dot{2}\end{array}$ & نَتْ & $\begin{array}{l}\dot{2} \\
\dot{z} \\
\vec{i} \\
\dot{i}\end{array}$ & $\stackrel{\leftrightarrow}{\dot{\omega}}$ & $\stackrel{\leftrightarrow}{\circ}$ \\
\hline 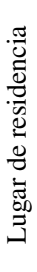 & 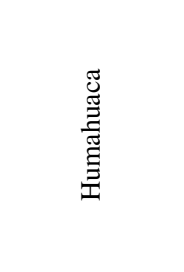 & 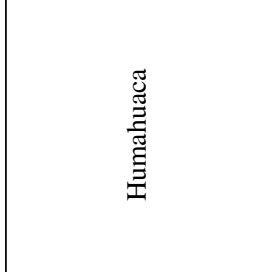 & 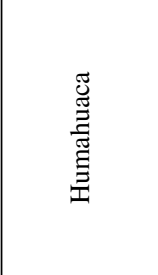 & 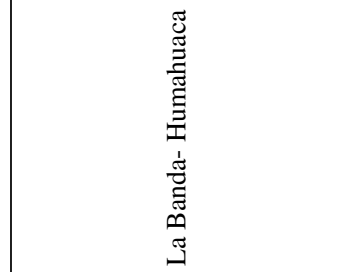 & 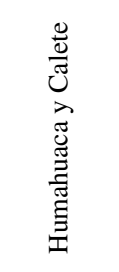 & 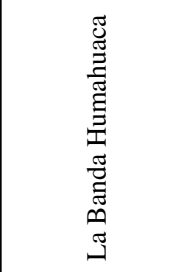 \\
\hline $\begin{array}{l}\frac{\pi}{0} \\
\frac{\pi}{\Phi}\end{array}$ & 흉유 & 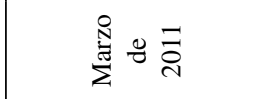 & 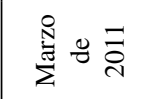 & 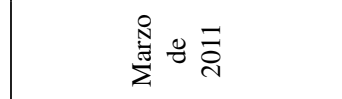 & $\bar{\Sigma}$ & $\overrightarrow{\vec{\alpha}} \overline{\vec{c}}$ \\
\hline ¿ & $a$ & $\stackrel{\circ}{\circ}$ & $=$ & $\simeq$ & $\cong$ & \pm \\
\hline
\end{tabular}




\begin{tabular}{|c|c|c|c|c|c|}
\hline & 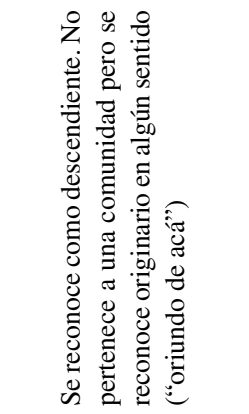 & 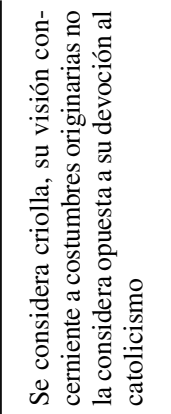 & 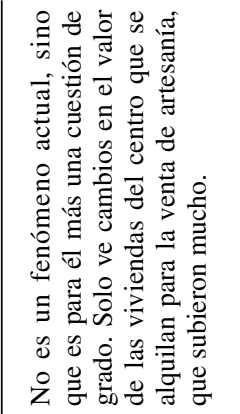 & 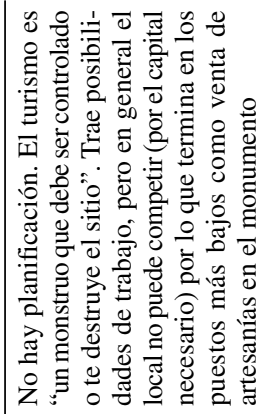 & 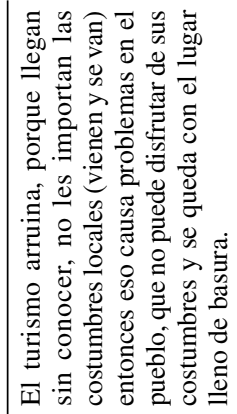 \\
\hline 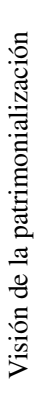 & 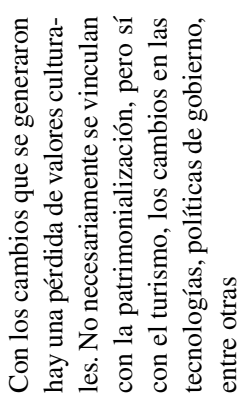 & 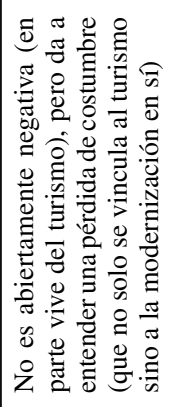 & 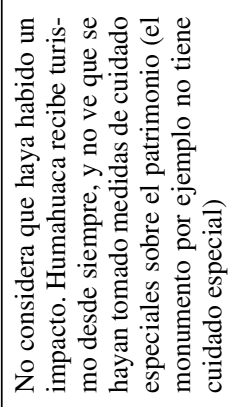 & 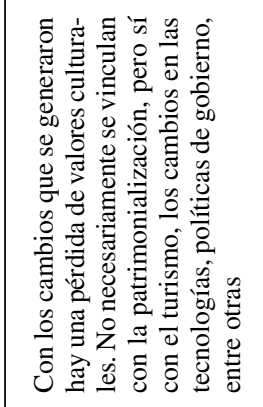 & 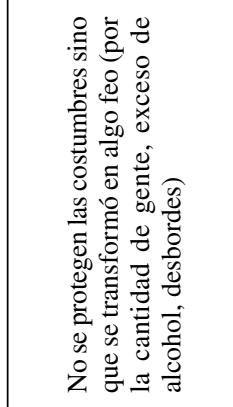 \\
\hline 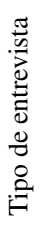 & 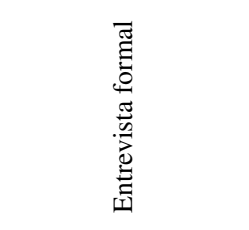 & 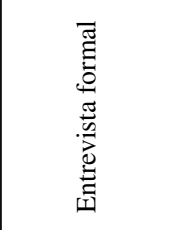 & 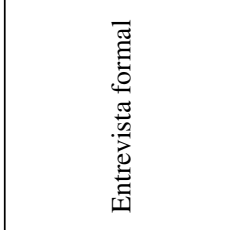 & 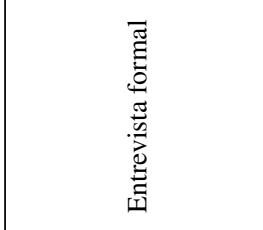 & 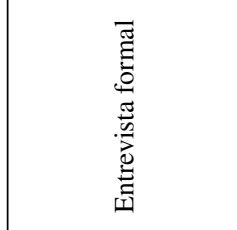 \\
\hline & 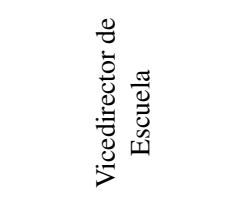 & 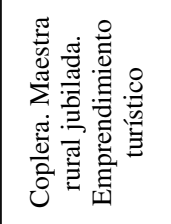 & 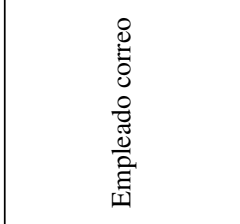 & 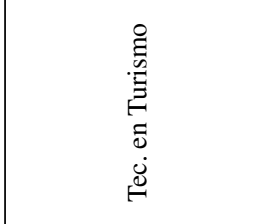 & $\begin{array}{l}\tilde{J} \\
\tilde{J} \\
\tilde{\Xi} \\
\tilde{\Xi} \\
\tilde{\Xi}\end{array}$ \\
\hline $\begin{array}{l}\text { D. } \\
\text { है } \\
\text { ż }\end{array}$ & $\dot{\theta}$ & $\begin{array}{l}3 \\
0\end{array}$ & $\begin{array}{l}\stackrel{H}{z} \\
\dot{z}\end{array}$ & $\dot{\varphi}$ & $\begin{array}{l}\dot{\Sigma} \\
\dot{0}\end{array}$ \\
\hline 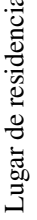 & 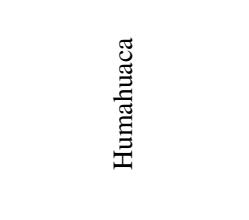 & 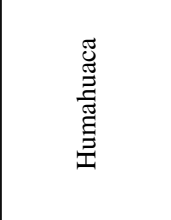 & 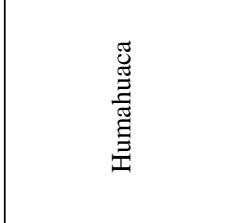 & 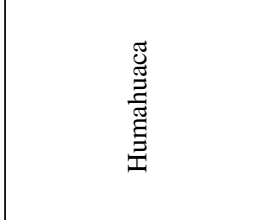 & 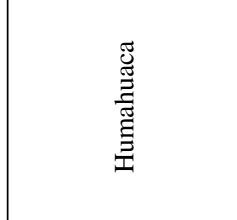 \\
\hline $\begin{array}{l}\frac{\pi}{0} \\
\\
\end{array}$ & $\dot{\vec{D}} \overline{\vec{n}}$ & $\dot{\vec{\theta}} \overline{\vec{\nabla}}$ & $\dot{\vec{\theta}} \overline{\vec{D}}$ & $\dot{\vec{\theta}} \overline{\vec{D}}$ & $\dot{\vec{\theta}} \overline{\vec{N}}$ \\
\hline 文 & 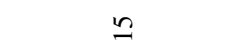 & $\mathscr{0}$ & $=$ & $\stackrel{\infty}{\sim}$ & $\curvearrowright$ \\
\hline
\end{tabular}




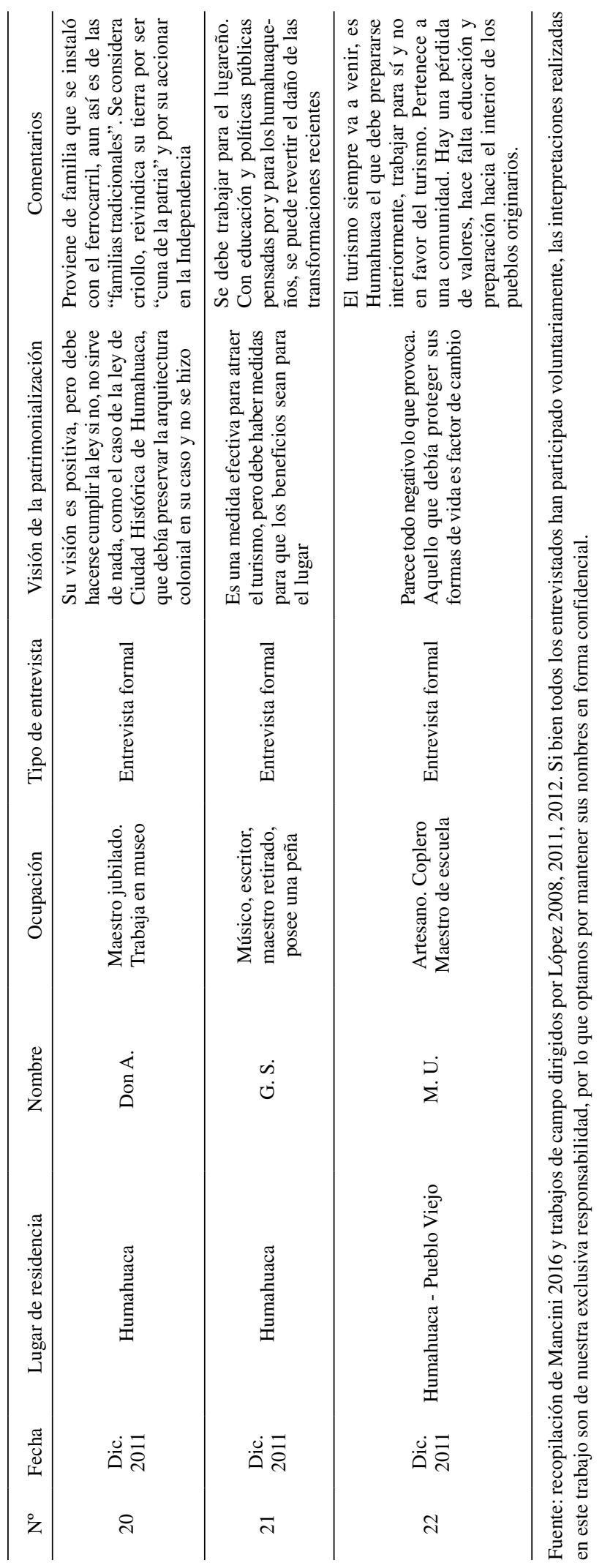


las ciencias y para las artes por medio de lo que se conoció como "Nativismo" y como se ve en la obra de Soto Avendaño (1987).

Por su parte, las autoridades municipales, la Iglesia católica, la escuela y la policía durante este período solo se limitaron a reproducir y garantizar estos discursos autorizados. Incluso, la promoción turística de la época reproducía esta narrativa de Peñas Blancas ofreciendo una excursión a pie con las siguientes explicaciones: "En este punto se han realizado excavaciones por cuenta de los museos de las ciudades de Buenos Aires y La Plata" (Peuser 1956); como "ruinas indígenas" (ACA 1958: 304305), o "ruinas de un pucará (...) de los que se extrajo interesante material arqueológico" (ACA 1958: 310).

La academia paulatinamente fue dejando de lado Peñas Blancas de las principales investigaciones y publicaciones arqueológicas. De algún modo, este sitio quedó un tanto al margen de las narrativas autorizadas, eclipsado por otros sitios declarados como representativos del período tardío y del impacto incaico y, a la vez, más accesibles para ser investigados. Como señalamos anteriormente, también recibe menos atención en las legislaciones que protegieron sitios de la Quebrada.

Por su parte, las narrativas de los pobladores locales convivían en la intimidad de la familia en diversos formatos, ya que no todos los pobladores incorporaron como propio el discurso homogeneizante del Estado-Nación con la figura del criollo como símbolo. Estimamos que es en este período cuando se comenzaron a desarrollar las narrativas locales que registramos en la actualidad de los sitios arqueológicos en general. Se trata de narrativas construidas en torno a historias de respeto, temor $\mathrm{o}$, a veces, indiferencia hacia los restos del pasado.

Por ejemplo, hay relatos de temor que explican por qué no hay que subir a los sitios arqueológicos, hurgar o excavar en ellos, y esto es porque pueden provocar enfermedades e, incluso, la muerte ${ }^{2}$. Este constituye un relato tan extendido en la región (Vilca 2011) que, incluso, algunos arqueólogos imitan a los pobladores locales en la realización de ceremonias en los sitios prehispánicos, entretejiendo liturgia andina con católica. Los arqueólogos las reproducen, saludando a la madre tierra, la Pachamama, con un brindis ritual que mínimamente debe incluir alcohol y hojas de coca y, a veces, la persignación.

En el caso específico del sitio Peñas Blancas, estos relatos explican por qué a veces los materiales del sitio no son los preferidos para ser utilizados en la construcción. De hecho, en 2011 el Prof. V. nos contó que hace aproximadamente 10 años la Municipalidad mandó camiones a sacar piedras de allí para la construcción y algunos pobladores las devolvieron porque se enfermaban. Otro ejemplo acerca del sitio son los registros de que, a principios de siglo XX, algunas comparsas y cuadrillas copleras desenterraban allí el carnaval ${ }^{3}$. Como se puede observar, estas no son narrativas que se opongan abiertamente al DPA, aun así, de modo simbólico lo enfrentan.

En cambio, aquellas narrativas locales que presentan a los sitios arqueológicos con indiferencia (como se puede deducir también por las intervenciones en el sitio que muestran las figuras 2 y 3 ), o simplemente como parte de una historia pasada, son el reflejo de la incorporación del discurso oficial por los pobladores, generalmente por medio de la escuela y la Iglesia. De aquí se derivan narrativas que oponen lo indígena a lo criollo, ligado a las luchas de la Independencia. Algunos pobladores locales manifestaron sentirse criollos, por sobre cualquier identidad indígena (kolla u omaguaca fueron las mencionadas). A veces reconocían un origen por fuera de Humahuaca como, por ejemplo, las familias que llegaron para la construcción del ferrocarril. Otros se reconocían humahuaqueños, oriundos de la región, pero no indígenas ${ }^{4}$.

En síntesis, puede decirse que en el transcurso del último tercio del siglo XX, y de forma más acentuada a partir del año 2003, se modificó la relación entre el DPA y otras narrativas en tensión. El contexto que facilitó este cambio habría comenzado con una crisis socioeconómica, que se agravó hacia el retorno de la democracia en 1983 y en la década de 1990, cuando gran parte de la población fue desplazada. De este modo, la gente que regresó a la quebrada ya no lo hizo a la vida rural de donde provenía, sino a las principales ciudades, Humahuaca y Tilcara. Fue por entonces cuando las políticas nacionales y provinciales promovieron también el turismo como fuente generadora de trabajo ${ }^{5}$.

De forma contemporánea, en Latinoamérica y en Argentina comenzó un proceso de reconfiguración de las identidades indígenas, "proceso por el cual la conciencia histórica nativa irrumpió en el dominio público para quebrar las narrativas homogeneizantes de los discursos míticos de la identidad nacional, dominadas por los componentes 'gaucho' y 'criollo"” (Lazzari 2012:2). Este 
contexto fue posible gracias a un marco legal que buscó garantizar los derechos indígenas ${ }^{6}$. Además, se visibilizaron las antiguas y nuevas luchas por la tierra y el territorio en la región, acompañados de metodologías nuevas: el uso de la acción directa, la expansión de la forma asamblea y la demanda de autonomía (López et al. 2016). Esta composición del conflicto social, trasladada a las particularidades de la Quebrada de Humahuaca, provocó una fractura en el DPA. Desde entonces todas las narrativas respecto del pasado se encuentran en manifiesta tensión y resulta difuso distinguir cuáles son las autorizadas y cuáles no.

En este proceso, distintos organismos internacionales (UNESCO, OIT) y el Estado Nacional a partir de diferentes legislaciones e instituciones cambiaron el discurso homogeneizante por el paradigma del multiculturalismo que permitió la multivocalidad. Aunque se buscaba democratizar la participación, garantizando el acceso de las comunidades a decidir de sus territorios, generalmente se trató de un proceso de forma que no siempre se ponía en práctica. Pero en la medida en que las comunidades fueron reconociendo sus derechos, aquellas garantías fueron demandadas para ser cumplidas ${ }^{7}$.

Los académicos, por su parte, han respondido a los cambios teóricos y a los nuevos contextos políticos y sociales con distintas estrategias o herramientas. Dentro de un continuum de posiciones, están los que toleran y cumplen con las nuevas disposiciones que exigen contemplar la decisión de la comunidad para dar conformidad a los trabajos arqueológicos. En el otro extremo están aquellos que proponen la multivocalidad como forma de trabajo (entre muchos otros, Gnecco 2004; Haber et al. 2010).

Entre los pobladores locales también existe una variedad de posturas frente al nuevo contexto. Algunos mantienen las narrativas pertinentes al sitio ya aludidas, mientras que otros reivindican el pasado indígena dentro del proceso de reconfiguración de las identidades. Por ejemplo, recientemente parte de las comunidades comenzaron a festejar en Peñas Blancas el Inti Raymi ${ }^{8}$, celebración de origen incaico, que según hemos registrado, se realiza en la Quebrada por lo menos desde $1992^{9}$. Además, la Comunidad Aborigen de Valiazo, reconocida como tal por el Instituto Nacional de Asuntos Indígenas y la Secretaría de Derechos Humanos, tiene ahora al sitio dentro de su territorio. Esta Comunidad solicitó a la Secretaría de Cultura de la provincia el rescate para una estructura de un entierro que se encontraba expuesta y, ante la llegada de los arqueólogos, la misma comunidad exigió la firma de un acuerdo para dar ellos destino final a esos restos humanos (Cruz y Seldes 2005). De este modo, consideramos que el discurso local comienza a institucionalizarse, al punto de que se construye una narrativa de la Nación Omaguaca que reivindica su derecho en relación con Peñas Blancas.

\section{Consideraciones finales}

La noción de patrimonio cultural, la disciplina arqueológica, las instituciones vinculadas y el sistema legal desarrollado para gestionar los bienes patrimonializados fueron generados en un mismo proceso que estuvo ligado a la formación del Estado argentino y a su proyecto de ciencia (Podgorny 2000; Endere 2001). Como resultado de este proceso de institucionalización del patrimonio cultural, los sitios y los vestigios "arqueológicos" de la Quebrada de Humahuaca son considerados de dominio público, bajo la tutela nacional y provincial (Berberián 1992; Endere 2001, entre otros).

A partir de este marco legal, queda claro que son la provincia y los arqueólogos quienes pueden generar conocimiento hacia el pasado a partir de estos sitios en particular. No obstante, las narrativas en torno al sitio Peñas Blancas se han ido modificando a lo largo del tiempo, cobrando mayor o menor legitimidad en relación con los intereses y visión del mundo que sostienen por detrás. De este modo, ellas nos permiten contraponer el sitio a otros lugares de Humahuaca que encarnan la visión "tradicional" de "lo humahuaqueño", apoyada por la épica de la Independencia, como muestra la creación del Monumento a los héroes de la Independencia.

Entonces, a pesar de la aparente convivencia actual entre las narrativas, producto del multiculturalismo, continúa latente una tensión entre los distintos discursos y su validez. De allí que, en situaciones puntuales, las narrativas entran en conflicto abierto, generando situaciones contradictorias algunas veces, o enfrentamientos en ocasiones violentos. En el caso de Peñas Blancas, las contradicciones se manifiestan en todos los actores involucrados. Así, no solo se pone en discusión de quién es el sitio y si hay que pedir permiso para excavarlo arqueológicamente, sino, también, se reflejan los usos y costumbres que hacen de este sitio un lugar por momentos sagrado, de protección (por respeto 
o temor), o como un recurso territorial y político en el que se pone en juego la adscripción étnica de las comunidades que incorporan este sitio como parte de su pasado.

\section{Agradecimientos}

Queremos agradecer a todas las personas de la Quebrada de Humahuaca que colaboraron con esta investigación. Asimismo, a Margarita Gastaldi, quien realizó algunas de las entrevistas aquí analizadas. Además, agradecemos a los evaluadores, cuyos comentarios nos permitieron mejorar una primera versión de este artículo. Los trabajos de campo fueron posibles gracias a varios subsidios: PIP-CONICET 242 (2010-2012), PICT-Redes 2007-2112 (20102012), UBA PRIP 2008-208, UBA CyT GEF 187 (2010-2012), y FNA mediante la Beca Nacional de Mancini (2013) y las becas grupales: 2008, 2012 y al grupo "Quiero Contarte" (2013).

\section{Referencias Citadas}

ACA

1958 Revista del Automóvil Club Argentino. Buenos Aires, Argentina

Barretto M.

2003 O imprescindível aporte das ciências sociais para o planejamento e a compreensão do turismo. Horizontes Antropológicos 9(20): 15-29.

Benedetti, A.

2010 Quebrada de Humahuaca: ¿hoya, unidad fisiográfica, región geográfica, ambiente o lugar? Estudio bibliográfico sobre la toponimia y el pensamiento geográfico regional argentino (siglos XIX y XX ). Registros 29: 111-138.

Berberián, E.E.

1992 La protección jurídica del patrimonio arqueológico en la República Argentina. $1^{\circ}$. Comechingonia, Córdoba, Argentina.

Boman, E.

1991 [1908] Antigüedades de la Región Andina de la República Argentina y el Desierto de Atacama. Universidad Nacional de Jujuy, San Salvador de Jujuy, Argentina.

Brackebusch, L.

1990 [1883] Por los caminos del norte. Universidad Nacional de Jujuy, San Salvador de Jujuy, Argentina.

Casanova, E.

1936 La Quebrada de Humahuaca. En Historia de la Nación Argentina I, pp. 207-248. Junta de Historia y Numismática Americana, Buenos Aires, Argentina.

Choay, F.

2007 Alegoría del Patrimonio. Editorial Gustavo Gili, Barcelona, España.

Cruz, P. y V. Seldes

2005 Patrimonio, identidad y práctica arqueológica en la Quebrada de Humahuaca (Jujuy, Argentina). En Patrimonio en el Noroeste Argentino. Otras Historias, editado por E. Belli y R. Slavutsky, pp. 167-195. Instituto Interdisciplinario de Tilcara, FFyL UBA, San Salvador de Jujuy, Argentina.

Endere, M.L.

2001 Patrimonio arqueológico en Argentina. Panorama actual y perspectivas futuras. Revista de Arqueología Americana (20): 143-158.

Endere, M.L y M.G. Chaparro

2013 El rol del patrimonio arqueológico en la valorización social del pasado. Visiones divergentes entre comunidades de Quebrada y Valles de Jujuy. En Al borde del imperio, paisajes sociales, materialidad y memoria en áreas periféricas del noroeste argentino, editado por V.I. Williams y M.B. Cremonte, pp. 109-141. Sociedad Argentina de Antropología, Buenos Aires, Argentina.

Endere, M.L.y M.G. Chaparro, y V.I. Williams

2013 Tolombón: arqueología y comunidad. En Al borde del imperio, paisajes sociales, materialidad y memoria en áreas periféricas del noroeste argentino, editado por V.I. Williams y M.B. Cremonte, pp. 209-220. Sociedad Argentina de Antropología, Buenos Aires, Argentina.

Fernández, J.

1982 Historia de la Arqueología Argentina. En Anales de Arqueología y Etnología, XXXIV-XXXV: Universidad Nacional de Cuyo, Mendoza, Argentina.

Fernández Distel, A.

1997 Jujuy. Diccionario Arqueológico. Editorial Milor, Salta, Argentina.

Fernández-Osco, M.

2010 La arqueología boliviana: ¿eslabón de la colonialidad? En Pueblos indígenas y arqueología en América Latina., editado por C. Gnecco y P. Ayala Rocabado. Ediciones Uniandes, Bogotá, Colombia.

Gatto, S. 1941 Ruinas del Pucará de Humahuaca. En Congreso de Historia Argentina del Norte y el Centro, pp. 130-142. Córdoba, Argentina.

Gnecco, C.

2004 La indigenización de las arqueologías nacionales. En Teoría arqueológica en América del Sur, editado por G.G. Politis y R.D. Peretti, pp. 119-128. INCUAPA UNICEN, Olavarría, Argentina.

González, A.R.

1985 Cincuenta Años de Arqueología del Noroeste Argentino (1930-1980): Apuntes de un Casi Testigo y Algo de Protagonista. American Antiquity 50(3): 505-517.

Grünewald, R. 2003 Turismo e etnicidade. Horizontes Antropológicos 9(20): 141-159.

Haber, A.F., W. Londoño, E. Mamaní y L. Roda

2010 Part of the conversation. Archaeology and locality. En Bridging the Divide: Indigenous Communities and Archaeology Into the 21st Century, editado por H. Allen y C. Phillips, pp. 81-92. Left Coast Press, Walnut Creek, Estados Unidos.

Janoschka, M.

2003 E1 turismo en la Quebrada. En La Quebrada, editado por C. Reboratti. La Colmena, Buenos Aires, Argentina. 
Karasik, G.A.

1994 Plaza grande y plaza chica: etnicidad y poder en la Quebrada de Humahuaca. En Cultura e identidad en el Noroeste argentino, editado por G.A. Karasik, pp. 35-75. Centro Editor de América Latina, Buenos Aires, Argentina.

Kojan, D.

2008 Paths of power and politics: historical narratives at the bolivian site of Tiwanaku. En Evaluating mutiple narratives. Beyond nationalist, colonialist, imperialist archaeologies, editado por J. Habu, C. Fawcett, y J.M. Matsunaga, pp. 69-85. Springer, Nueva York, Estados Unidos.

Lazzari, M.

2012 El pasado-presente como espacio social vivido: identidades y materialidades en Sudamérica y más allá (primera parte). Nuevos Mundos Mundos Nuevos [En línea] Questions du temps présent

López, M. A.

2011 Chuchos o Cutis y Chacpas. El culto a los cadáveres de infantes y adultos dentro ollas según los extirpadores de idolatrías andinas. Andes [en línea] vol. 22.

López, M.A., C.E. Mancini, y V.J. Acevedo

2016 ¿Es posible una arqueología sin excavación? El caso de la Quebrada de Humahuaca en el contexto sudamericano. Latin American Research Review 51 (4):102-119

Mancini, C.E.

2016 Arqueología, patrimonio y usos del pasado. Las transformaciones territoriales de la Quebrada de Humahuaca hacia un Paisaje Cultural. Tesis para optar al título de Doctora de la Universidad de Buenos Aires, área arqueología, Facultad de Filosofía y Letras, UBA. Buenos Aires, Argentina.

Mancini, C.E. y C.I. Tommei

2012 Transformaciones de la Quebrada de Humahuaca (Jujuy) en el siglo XX: entre destino turístico y bien patrimonial. Registros 8(9):97-116.

Márquez Miranda, F.

1945 Dos investigaciones en el Pucara de Humahuaca (1933 y 1944). Revista del Museo de La Plata NS:123-141.

Menezes Ferreira, L. y J. Mujica Sallés

2012 Construcciones alternativas: Apuntes sobre las relaciones entre arqueología , patrimonio cultural y diversidad. Estudios Sociales del NOA / Nueva Serie (12):161-171.

Nash, D. y Smith, V.

1991 Anthropology and tourism Annal of Tourism Research 18(1): 12-25.

Nielsen, A.E.

2001 Evolución social en Quebrada de Humahuaca (AD 700-1636). En Historia Argentina Prehispánica. Tomo I, editado por E.E. Berberián y A.E. Nielsen, pp. 171-264. Editorial Brujas, Córdoba, Argentina.

Olivera, D.

1994 A corazón abierto: reflexiones de un arqueólogo del NOA. Rumitacana 1:7-12.

Otero, $\mathrm{C}$.

2013 La arqueología en el relato oficial del Estado Nacional. El caso del Pucará de Tilcara (Jujuy, Argentina). Arqueología Suramericana /Arqueología Sul-Americana 6(1,2):87-112. Palma, J.R.

1991 Arquitectura Inca Provincial en Peñas Blancas, Quebrada de Humahuaca. Comechingonia. Revista de Antropología e Historia 8(7):5-14.
Perez Gollán, J.M.

1996 Comentario. Relaciones de la Sociedad Argentina de Antropología 21:359-366.

Peuser

1956 Guía Peuser de Turismo. Año 14. Casa Peuser, Buenos Aires, Argentina.

Podgorny, I.

2000 Archaeology and education in Argentina. Antiquity 74(283):151-155.

Podgorny, I.

2004 "Tocar par creer". La arqueología en la Argentina, 1910-1940. Anales del Museo de América 12:147-182.

Prats, L.

2005 Concepto y gestión del patrimonio. Cuadernos de Antropología Social (21):17-35.

Raffino, R.A.

2007 Poblaciones indígenas en Argentina. Urbanismo y proceso social precolombino. Emecé, Buenos Aires, Argentina.

Ramundo, P.S.

2007 Los aportes de los investigadores pioneros a la arqueología del Noroeste argentino. En Temas de Historia Argentina y Americana, Pontificia Universidad Católica Argentina, Instituto de Historia Argentina y Americana, Facultad de Filosofía y Letras, XI, pp. 179-218. Buenos Aires, Argentina.

Rebaudi Basavilbaso, O.

1935 Jujuy. Historia - Bellezas. Roldan Editor, Buenos Aires, Argentina.

Reboratti, C., J.C. García Codrón, M.E. Albeck, H. Castro, y

M. Arzeno

2003 Una visión general de la Quebrada. En La Quebrada, editado por C. Reboratti, pp. 17-46. La Colmena, Buenos Aires, Argentina.

Smith, L.

2012 Discourses of heritage: implications for archaeological community practice. Nuevos Mundos Mundos Nuevos [En línea] Questions du temps présent: 1-11.

Smith, V

1980 Anthropology and tourism: A science-industry evaluation. Annal of Tourism Research 7(1): 13-33.

Smith, V.

1992 Introducción. Hacia una definición de la naturaleza del turismo. En Anfitriones e invitados. Antropología del turismo, editado por V. Smith, pp. 15-41. Endymion, Madrid.

Soto Avendaño, E.

1987 El Monumento a la Independencia en Humahuaca. Talleres Gráficos del Banco de la Provincia de Jujuy, San Salvador de Jujuy, Argentina.

Suárez Giambra, L.

2010 Huacalera. La "Finca Monterrey". Un lugar olvidado en la Quebrada de Humahuaca. Editorial Milor, San Salvador de Jujuy, Argentina.

Tommei, C. I.

2016 De ciudad huerta a pueblo boutique. Transformaciones territoriales en Purmamarca (provincia de Jujuy) a partir de los procesos de patrimonialización y turistificación (1991-2011). Tesis para optar al título de Doctora de la Universidad de Buenos Aires, área geografía, Facultad de Filosofía y Letras, UBA. Buenos Aires, Argentina.

Troncoso, C.A.

2009 Patrimonio y redefinición de un lugar turístico. La Quebrada de Humahuaca, Provincia de Jujuy, Argentina. Estudios y Perspectivas en Turismo 18: 144-160. 


\section{Vilca, M.}

2011 Piedras que hablan, gente que escucha: la experiencia del espacio andino como un "otro" que interpela. Una reflexión filosófica. En Biografías de paisajes y seres. Visiones

\section{Notas}

1 Por ejemplo, en Humahuaca la Ley Nacional № 11.383/1933 establece la construcción de un "Monumento a los Héroes de la Independencia"

2 "Yo les decía que había visto los virques y los cántaros y la gente de ahí me decía que "¡Noooo! Eso es de la gente de antes" No, ellos no enterraban a cualquiera. Lo metían dentro de un virque o de un cántaro o una olla y los dejaban ahí. Ahí en medio de las peñas. Pero no he visto con el sol... Claro, con la sombra están bien. Pero no, yo tengo miedo. No, yo he visto muchas cosas allî" (Entrevista a S.T. 2011).

3 "En realidad la gente lo conoce como un sitio arqueológico. Pero nosotros, dentro de la comunidad, estábamos pensando ahora, que sobre la parte superior de lo que es Peñas Blancas.... Un poco más allá de donde está la virgen, ahí desenterraban [el carnaval] hace muchos años, la cuadrilla de copleros de 1800 . Y después fue trasladada, digamos, el mojón de la cuadrilla, fue trasladada a donde lo desenterramos actualmente. Eso fue hace más de 40 años" (Entrevista a N.S. 2011).

4 Entrevistas a S.T.; J.D.; O.W. y O.M. (2011).

5 Por ejemplo, la Secretaría de Turismo de la Nación declaró en 1993 de interés nacional a la Quebrada de Humahuaca desde la arqueología sudamericana, editado por D. Hermo y L. Miotti, pp. 67-74. Encuentro Grupo Editor - Editorial Brujas, Córdoba, Argentina.

"por constituir todo un testimonio de nuestra identidad y uno de los más significativos bienes de nuestro patrimonio natural, histórico, cultural y arqueológico" (Resolución 242/1993).

6 Principalmente, la Ley Nacional $N^{\circ} 23.302 / 1985$, Art. 50 de la Constitución Provincial de Jujuy de 1986, Convenio sobre los Pueblos Indígenas y Tribales $\mathrm{N}^{\circ} 169$ de la Organización Internacional del Trabajo (OIT) y del Art. 65 Inc. 17 de la Constitución Nacional de 1994.

7 Por ejemplo, según la Defensoría del Pueblo, se llevó a cabo por primera vez en Argentina un proceso de Consulta Previa Informada sin intervención judicial. Fuente: http:// blogdeprensa.com.ar/gacetillas/1245-por-primera-vezen-la-argentina-se-llevo-a-cabo-un-proceso-de-consultaprevia-libre-e-informada-a-comunidades-indigenas

8 Por ejemplo: http://www.continental.com.ar/noticias/sociedad/aborigenes-festejan-en-jujuy-el-inti-raymi/20110621/ nota/1492702.aspx ; http://www.eltribuno.info/ celebracion-del-inti-raymi-todo-jujuy-n38650

9 Así nos fue relatado durante un reciente trabajo de campo (Julio 2016) y ha recopilado Suárez Giambra (2010) para Huacalera, donde se comenzó a festejar el Inti Raymi. 

ANDROS IMPRESORES

www.androsimpresores.cl 

